\title{
Financial Intermediation and Capital Reallocation
}

\author{
Hengjie Ai, Kai Li, and Fang Yang *
}

November 16, 2014

\begin{abstract}
We develop a general equilibrium framework to quantify the importance of intermediated capital reallocation in affecting macroeconomic fluctuations and asset returns. In our model, financial intermediaries intermediate capital reallocation between low productivity firms with excess capital and high productivity firms who need credit. Because lending contracts cannot be perfectly enforced, capital misallocation lowers aggregate productivity when intermediaries are financially constrained. As a result, shocks originated from the financial sector manifest themselves as fluctuations in total factor productivity and account for most of the business cycle variations in macroeconomic quantities. Our model produces a pro-cyclical capital reallocation and is consistent with the stylized fact that the volatilities of productivity are counter-cyclical at both the firm and the aggregate level. On the asset pricing side, our model matches well moments of interest rate spreads in the data and successfully generates a high and counter-cyclical equity premium.
\end{abstract}

Keywords: Financial Intermediation, Capital Reallocation, Volatility, Equity Premium

${ }^{*}$ Hengjie Ai (hengjie@umn.edu) is at the Carlson School of Management of University of Minnesota, Kai Li (kaili@ust.hk) is associated with Hong Kong University of Science and Technology, and Fang Yang (fyang@lsu.edu) is associated with Louisiana State University. We thank Junyan Shen for his participation in the early stage of the paper. We thank Ravi Bansal, Andrea Eisfeldt, Murray Frank, Amir Yaron, seminar participants at the University of Cincinnati, Georgia Institute of Technology, Simon School of Business at the University of Rochester, and the Capital Markets program in 2014 NBER Summer Institute for their helpful comments. The usual disclaimer applies. 


\section{Introduction}

The purpose of this paper is to develop a general equilibrium framework to understand quantitatively the role of financial intermediation in affecting macroeconomic fluctuations and asset prices through the capital reallocation mechanism. The recent great recession is not only marked by disruptions of financial intermediation but also by sharp increases in capital misallocation and sharp decreases in capital utilization. More generally, measured total factor productivity is highly negatively correlated with measures of capital misallocation and positively correlated with measures of capital utilization.

In Figure 1, we plot total factor productivity (TFP) (dashed line) against measured capital misallocation, where both series are HP filtered. We follow a similar procedure as Hsieh and Klenow (2009) and measure capital misallocation by the variance of the crosssectional distribution of log marginal product of capital within narrowly defined industries (classified by the four-digit standard industry classification code). We use a first order Taylor approximation as described in Appendix B to translate the dispersion measure into units of TFP gains. ${ }^{1}$ The two series track each other remarkably closely, and this pattern is robust to alternative measures of TFP and misallocation. In Figure 2, we plot the same measure of capital misallocation and log capital utilization rates for the same period. Clearly, both series are pro-cyclical and highly correlated with each other.

We develop a model where disruptions of financial intermediation generates endogenous time variations in capital misallocation and capital utilization. We show that shocks to agency frictions are capable of generating large recessions and significant asset market fluctuations through the capital misallocation mechanism.

Our model emphasizes the role of financial intermediaries in facilitating capital reallocation among firms with heterogenous productivity. We assume incomplete markets and agency frictions (limited enforcement of financial contracts) as in Gertler and Kiyotaki (2010). Our novelty is the introduction of heterogenous productivity and imperfect substitution among firms' output. Both features of the model are designed to motivate the need for reallocating capital and labor across firms with different productivity and to quantify the benefit of such.

In the model, firms are subject to idiosyncratic productivity shocks. It is efficient to reallocate capital and labor from low productivity firms with excess capacity to high productivity firms who need to expand their operation upon the realization of such shocks. This arrangement requires high productivity firms to borrow through financial intermedi-

\footnotetext{
${ }^{1}$ We detail the data construction in Appendix B.
} 
aries, who finance the investment by borrowing from households and low productivity firms. However, the debt contract between financial intermediaries and lenders are subject to limited enforcement. A worsening of the agency frictions impedes banks' ability to borrow limits the efficiency of capital reallocation. When this happens, because resource allocation is inefficient, the cross-sectional dispersion of marginal product of capital widens and measured total factor productivity declines. In the extreme case, when all intermediaries in the economy are constrained, some of the productive capital cannot be utilized and output declines sharply.

In our quantitative exercises, we consider three specifications of our model: a benchmark model where shocks originated directly from the financial sector, a model with total factor productivity shocks, and a model with capital depreciation shocks. Consistent with the previous literature, we find that in the model with productivity shocks, the amplification mechanism is present but quantitatively small: on average, the presence of financial frictions increases the macroeconomic volatility by about $10 \%$. The model with capital depreciation shocks, when calibrated to match the volatility of aggregate output, also generate fairly small variations in capital misallocation. Our benchmark model with financial shocks generate most of the macroeconomic fluctuations through capital misallocation and capital utilization.

Our model makes several contributions. First, it provides a micro-foundation for total factor productivity shocks and generate macroeconomic fluctuations without resorting to technology regress. In our model, variations in the efficiency of capital reallocation are responsible for most of the fluctuations in output and measured total factor productivity. Our theory features shocks to agency frictions that affect intermediaries's borrowing capacity and we use empirical evidence on interest rates to discipline our quantitative exercise.

Second, our model generates endogenous countercyclical volatility in macroeconomic quantities and asset prices. This is due to the inherit asymmetry in the amplification mechanism. On one hand, a worsening of financial frictions lowers total output and bank net worth, which increases the leverage of the banking sector, making the economy more vulnerable to additional shocks to the financing constraint. On the other hand, shocks that improve banks' financing constraints lower leverage and reduce macroeconomic volatility. In the extreme case where banks are unconstrained, aggregate volatility is zero in the absence of productivity shocks.

Third, our model produces a significantly higher volatility of equity returns than standard $\mathrm{RBC}$ models. The inability of standard RBC model in generating significant fluctuations in asset prices is well known. To match the high volatility of investment in the data, these 
models typically require a very low curvature of investment adjustment cost function. Low adjustment cost implies that the variation of Tobin's Q, which equals the marginal cost of investment in equilibrium, must be low. For example, the volatility of Tobin's $\mathrm{Q}$ in our model with exogenous TFP shocks but without financing frictions is about $0.5 \%$ per year. The volatility of Tobin's $\mathrm{Q}$ in our model with financing constraints is about 3.5\% per year. Capital is valuable in our model not only because it delivers future cash flows, but also because it may relax intermediaries' borrowing constraints in the future. Variations in financial market frictions affect the marginal cost of financing constraints and translate into variations in the price of capital.

Our paper belongs to the literature on macroeconomic models with financial frictions. ${ }^{2}$ The papers that are most related to our are Gertler and Kiyotaki (2010), Brunnermeier and Sannikov (2014), He and Krishnamurthy (2014), and Rampini and Viswanathan (2014). Our model builds directly on Gertler and Kiyotaki (2010) and extends their model in several dimensions. First, we allow heterogeneity in firms' productivity and study the role of financial intermediary in facilitating capital reallocation in the cross section, whereas Gertler and Kiyotaki (2010) focus on how financial frictions affect intertemporal investment decisions. As a result, the amplification mechanism in our model is much stronger, because financial frictions affect current period output directly. Second, we assume that firms' output are imperfect substitutes. This allows us to calibrate the elasticity of substitution among varieties as in Hsieh and Klenow (2009) and quantify importance of capital reallocation. Third, we develop a recursive method to solve the model to account for the occasionally binding constraints, which is the key mechanism that generates countercyclical volatility and countercyclical equity premium in our model. Gertler and Kiyotaki (2010) linearize their model around the deterministic steady-state, where financial constraints are always binding.

Several papers emphasize the importance of capital reallocation in understanding credit market frictions. For example, Eisfeldt and Rampini (2006), Eisfeldt and Rampini (2008), Shourideh and Zetlin-Jones (2012), Kurlat (2013), Chen and Song (2013), Fuchs et al. (2013), and Li and Whited (2014). Our paper falls into this category. Eisfeldt and Rampini (2006) provide empirical evidence that the amount of capital reallocation is procyclical and the benefit of capital reallocation is counter-cyclical. They also present a model where the cost

\footnotetext{
${ }^{2}$ A partial list of this literature include Bernanke and Gertler (1989), Carlstrom and Fuerst (1997), Kiyotaki and Moore (1997), Kiyotaki and Moore (2005), Bernanke et al. (1999), Krishnamurthy (2003), Kiyotaki and Moore (2008), Mendoza (2010), Gertler and Karadi (2011), Jermann and Quadrini (2012), He and Krishnamurthy (2012), He and Krishnamurthy (2013), and Li (2013). Quadrini (2011) and Brunnermeier et al. (2012) provide comprehensive reviews of this literature.
} 
of capital reallocation is correlated with TFP shocks to rationalize these facts. Eisfeldt and Rampini (2008), Kurlat (2013), Fuchs et al. (2013), and Li and Whited (2014) focus on adverse selection problems, while this paper focus on limited commitment of financial contracts. In addition, we explicitly allow for a financial intermediary sector in our model and we use empirical evidence on bank loans and interest rate spreads to discipline our quantitative exercise. Finally, different from all of the above models, we study asset prices and macroeconomic quantities jointly in our model, in particular, the dynamics of macroeconomic volatilities and expected returns.

The idea that shocks may originate directly from the financial sector and affect economic activities follows Jermann and Quadrini (2012). Different from Jermann and Quadrini (2012), our paper focus on financial intermediation and capital reallocation and their connections with the macroeconomy.

Our paper is also related to the literature on asset pricing in production economies and recursive preferences. ${ }^{3}$ The endowment based long-run risks literature emphasizes the importance of volatility shocks in understanding asset prices (for example, Bansal and Yaron (2004), Bansal et al. (2010)). However, standard real business cycle models typically produce very little amount of endogenous time variation in the volatility of macroeconomic quantities, negligible in terms of its risk premium. Our model endogenously generates coutercyclical volatility in consumption, stochastic discount factor, and equity returns because of the inherit asymmetry of the amplification mechanism.

The rest of the paper is organized as follows. We provide a summary of some stylized facts that motivate the development of our model in Section II. We describe the model setup in Section III. In Section IV, we characterize the solution to our model in the two-period case and use this setup to discuss the intuition for the main insights of the fully dynamic model. In Section V, we develop a recursive method to construct Markov equilibria in the fully dynamic model and a numerical procedure to solve for such equilibria. We calibrate our model and evaluate its quantitative implications on macroeconomic quantities and asset prices in Section VI. Section VII concludes.

\footnotetext{
${ }^{3}$ For example, Tallarini (2000), Kaltenbrunner and Lochstoer (2010), Croce (2010), Papanikolaou (2001), Ai et al. (2013), Gourio (2012), Kung and Schmid (2013), Kogan and Papanikolaou (2012b), Favilukis and Lin (2013). For a recent survey of this literature, see Kogan and Papanikolaou (2012a).
} 


\section{Stylized Facts}

In this section, we provide some stylized facts that motivate the development of our theoretical model. The first fact is about the business cycle properties of the total volume of intermediated loans:

1. The total volume of bank loans is procyclical. It is negatively correlated with measures of volatility and capital misallocation.

The above fact is what motivates our theory of financial intermediation and its connection with capital reallocation. We calculate the total volume of bank loans of the non-financial corporate sector in the U.S. from the Flow of Funds Table. Total bank loans are calculated as the difference between total corporate credits and corporate bond issuance. The details of the data construction can be found in Appendix B.

We plot the annual changes in the total volume of bank loans and the GDP growth rate of the U.S. economy in Figure 3. The shaded areas indicate NBER defined recessions. It is clear that the total volume of bank loans is strongly procyclical. The correlation between the two series is 0.42 at the annual level.

In Figure 4, we plot the annual changes in the total volume of bank loans and the measured cross-sectional dispersion in the marginal product of capital from the COMPUSTAT dataset. We provide the details of the construction of the dispersion measure in Appendix B. Clearly, the innovations of the total volume of bank loans are strongly negatively correlated with our measure of capital misallocation - the correlation of the two series is -0.43 at the annual frequency. This is consistent with the key mechanism of our model: when banks are constrained, the total volume of bank loans decreases, and capital reallocation is less efficient.

We plot the annual changes in the total volume of bank loans and aggregate stock market volatility in Figure 5. Stock market volatility is calculated by aggregating realized variance of monthly returns. The correlation between the two time series is about -0.25 at the annual level. We also plot the cross-sectional dispersion of firm profit in Figure 6. It is clear that changes in the total volume of bank loans is strongly negatively correlated with both measures of volatility.

The rest of the stylized facts are well-known. We therefore do not provide detailed discussion here but refer to the relevant literature. The second fact is about the 
business cycle properties of capital reallocation. This is documented in Eisfeldt and Rampini (2006).

2. The amount of capital reallocation is procyclical and the cross-sectional dispersion of marginal product of capital is countercyclical.

The third, fourth and fifth facts are about the cyclical properties of the volatility of macroeconomic quantities and asset returns and are well-known in the macroeconomics literature and the asset pricing literature, for example, Bloom (2009), Bansal et al. (2012) and Campbell et al. (2001).

3. The volatility of macroeconomic quantities, including consumption, investment, and aggregate output is countercyclical.

4. The volatility of aggregate stock market return is also countercyclical. Equity premium and interest rate spreads are countercyclical.

5. The volatility of idiosyncratic returns on the stock market is countercyclical.

In the following sections, we setup and analyze a general equilibrium model with financial intermediation and capital reallocation to provide a theoretical and quantitative framework to interpret the above facts.

\section{Model Setup}

\section{A Non-financial Firms}

The specification of non-financial firms in our model follows the standard monopolistic competition setup in the capital misallocation literature, for example, Hsieh and Klenow (2009). There are three types of non-financial firms, intermediate goods producers, final goods producers and investment goods producers. Because non-financial firms do not make intertemporal decisions in our model, we suppress the dependence of prices and quantities on state variables in this subsection.

Final goods are produced by a representative firm on a perfectly competitive market using a continuum of intermediate inputs. We normalize the price of final goods to one and 
write the profit maximization problem of the final goods producer as:

$$
\begin{aligned}
& \max \left\{Y-\int_{[0,1]} p_{j} y_{j} d j\right\} \\
& Y=\left[\int_{[0,1]} y_{j}^{\frac{\eta-1}{\eta}} d j\right]^{\frac{\eta}{\eta-1}},
\end{aligned}
$$

where $p_{j}$ and $y_{j}$ are the price and quantity of input $j$ produced on island $j$, respectively. The parameter $\eta$ is the elasticity of substitution among varieties. The constant return to scale technology and the fact that the final goods market is perfectly competitive imply that final goods producers earn zero profit in equilibrium. In this case, final goods producer's demand function for input variety $j$ can be written as:

$$
p_{j}=\left[\frac{y_{j}}{Y}\right]^{-\frac{1}{\eta}} .
$$

There is continuum of monopolistically competitive intermediate goods producers indexed by $j \in[0,1]$, each producing a different variety on a separate island. ${ }^{45}$ We use $j$ as the index for both the intermediate input and the island on which it is produced. The profit maximization problem for the producer on island $j$ is given by:

$$
\begin{gathered}
D_{F}(j)=\max \left\{p_{j} y_{j}-M P K_{j} \cdot k_{j}-M P L \cdot l_{j}\right\} \\
\text { subject to }: \quad p_{j}=\left[y_{j} / Y\right]^{-\frac{1}{\eta}} \\
y(j)=A a_{j} k_{j}^{\alpha} l_{j}^{1-\alpha} .
\end{gathered}
$$

Here, the production of variety $j$ requires two factors, capital $k_{j}$ and labor $l_{j}$. $A$ is the aggregate productivity common across all firms. $a_{j}$ is island $j$-specific idiosyncratic productivity shock, which we assume to be i.i.d. over time. $M P K_{j}$ is the rental price of capital on island $j$ and $M P L$ is the economy wide wage rate. Because our focus is on capital reallocation across islands with different idiosyncratic productivity shocks, we allow the rental price of capital to be island specific, but assume frictionless labor market across the whole economy. We use $D_{F}(j)$ to denote the total profit of firm $j$, which is paid to households as dividend.

\footnotetext{
${ }^{4}$ In the rest of the paper, we suppress the state space of varieties, $[0,1]$ to save notation.

${ }^{5}$ We use the terminology "island" to emphasize that capital cannot move freely among producers of different input varieties. The details of capital market frictions is introduced in Section
} 
We adopt a convenient normalization,

$$
\int a_{j}^{\eta-1} d j=1
$$

As will become clear later, the above condition implies that the average idiosyncratic productivity is one and total output is given by the standard Cobb-Douglas production function, $A K^{\alpha} N^{1-\alpha}$ in the absence of misallocation.

We assume, for simplicity, that there are only two possible realizations of idiosyncratic productivity shocks, $a_{H}$ and $a_{L}$. We denote

$$
\operatorname{Pr} o b\left(a=a_{H}\right)=\pi ; \quad \operatorname{Pr} o b\left(a=a_{L}\right)=1-\pi .
$$

In this case, assumption (4) can be written as

$$
\pi a_{H}^{1-\eta}+(1-\pi) a_{L}^{1-\eta}=1
$$

Finally, the representative investment goods producer produces investment goods with a constant return to scale and convex cost function. Their profit maximization problem can be written as:

$$
D_{I}=\max \{q I-H(I, K)\}
$$

where $q$ denotes the price of investment goods, $D_{I}$ denotes the total profit of the investment goods producing firm, $I$ denotes the total amount of investment goods produced, and $K$ denotes the total capital stock of the economy. In equation (7), $H(I, \bar{K})$ is the cost of investment, including adjustment cost. We assume a standard quadratic adjustment cost:

$$
H(I, K)=I+\frac{1}{2} h\left(\frac{I}{K}-i^{*}\right)^{2} K
$$

where $h$ is positive constant, and $i^{*}$ is the steady-state investment-to-capital ratio.

\section{B Household}

There is a representative household with recursive preferences with constant risk aversion $\gamma$ and constant IES $\psi$. As in Gertler and Kiyotaki (2010), market is incomplete and household can only invest in a risk-free deposit account with financial intermediaries. We assume (and later verify) that household's utility maximization problem can be written in a recursive 
fashion:

$$
\begin{gathered}
V(\mathbf{Z}, W)=\max _{C, B_{f}}\left\{(1-\beta) C^{1-\frac{1}{\psi}}+\beta\left(E\left[V\left(\mathbf{Z}^{\prime}, W^{\prime}\right)^{1-\gamma} \mid \mathbf{Z}\right]\right)^{\frac{1-1 / \psi}{1-\gamma}}\right\}^{\frac{1}{1-1 / \psi}} \\
C+B_{f}=W \\
W^{\prime}=B_{f} R_{f}(\mathbf{Z})+\int D_{F}(i)\left(\mathbf{Z}^{\prime}\right) d i+D_{I}\left(\mathbf{Z}^{\prime}\right)+\int D_{B}(i)\left(\mathbf{Z}^{\prime}\right) d i+M P L\left(\mathbf{Z}^{\prime}\right)-\chi q\left(\mathbf{Z}^{\prime}\right) \bar{K}^{\prime} .
\end{gathered}
$$

In the above maximization problem, we assume that there exist a vector of Markov state variables $\mathbf{Z}$, the law of motion of which will be specified later, that completely summarize the history of the economy. ${ }^{6}$ Taking the equilibrium interest rate $R_{f}(\mathbf{Z})$, the dividend payment from intermediate goods producers, $\left\{D_{F}(i)(\mathbf{Z})\right\}_{i \in[0,1]}$, that from investment goods producers, $D_{I}(\mathbf{Z})$, and that from the banks, $\left\{D_{B}(i)(\mathbf{Z})\right\}_{i \in[0,1]}$ as given, the household makes its optimal consumption and saving decisions given its initial wealth level, $W{ }^{7}$ Household income includes total savings in the bank account, $B_{f} R_{f}(\mathbf{Z})$, total dividends (monopolistic rents) from intermediate goods producers, $\int D_{F}(i)\left(\mathbf{Z}^{\prime}\right) d i$, total dividend payment from banks, $\int D_{B}(i)\left(\mathbf{Z}^{\prime}\right) d i$, and total labor income, $M P L(\mathbf{Z})$. Here we assume that the household is endowed with one unit of labor in every period, which it supplies inelastically to firms.

The household owns the ultimate claims of all assets in the economy. As in Gertler and Kiyotaki (2010), we assume that the household owns the capital stock of the economy only indirectly through the bank. Therefore, household income does not include capital income directly but only dividend payment from banks. Also similar to Gertler and Kiyotaki (2010), we assumes that household must involuntarily inject $\chi$ fraction of the total value of capital stock, $\chi q\left(\mathbf{Z}^{\prime}\right) \bar{K}^{\prime}$ into the banking sector in every period. This assumption ensures that the net worth of the banking sector will never be depleted in equilibrium.

\section{Financial Intermediaries}

There is one financial intermediary on each island. ${ }^{8}$ Financial intermediaries are the only agents in the economy who have access to the capital markets.

\footnotetext{
${ }^{6}$ In another words, we will focus on Markov equilibria with state space $\mathcal{Z}$, where $\mathcal{Z}$ is the set of all possible realizations of $\mathbf{Z}$. There is no general uniqueness and existence result that can be applied to the Markov equilibrium in our model. In Section IV, we construct such an equilibrium and our numerical result suggests such equilibria is unique.

${ }^{7}$ We use the term financial intermediary and bank interchangeably.

${ }^{8}$ Because financial intermediaries on each island face competitive capital markets, one should interpret our model as having a continuum of identical financial intermediaries on each island.
} 
We assume that the representative household is divided into bankers and workers, and there is perfect consumption insurance between bankers and workers within the household. Under this assumption, banks evaluate future cash flows using the "stochastic discount factor" implied by the marginal utility of the household: ${ }^{9}$

$$
M^{\prime}=\beta\left(\frac{C\left(\mathbf{Z}^{\prime}, W^{\prime}\right)}{C(\mathbf{Z}, W)}\right)^{-\frac{1}{\psi}}\left(\frac{V\left(\mathbf{Z}^{\prime}, W^{\prime}\right)}{\left(E\left[V\left(\mathbf{Z}^{\prime}, W^{\prime}\right)^{1-\gamma} \mid \mathbf{Z}\right]\right)^{\frac{1}{1-\gamma}}}\right)^{\gamma-\frac{1}{\psi}}
$$

A new generation of banks enter into the economy at the end of every period after the completion of production. As in Gertler and Kiyotaki (2010), we assume that capital and net worth moves freely across islands at the end of every period after the completion of currentperiod production and before the realization of next-period shocks. This is a simplifying assumption that avoids having to keep track of the cross-sectional distribution of net worth and capital as a state variable. As will become clear later, because island specific productivity shocks are i.i.d. over time, the ratio of capital and net worth must equalize across islands at the end of each period. In addition, there is an economy wide price for capital at the end of each period, which we denote $q(\mathbf{Z})$.

Consider a bank who enters into a period with initial net worth $N$. Given the endof-period price of capital $q(\mathbf{Z})$, the bank chooses the total amount of borrowing from the household, $B_{f}$, amount of borrowing from peer banks, $B_{I}$, and the total amount capital stock for the next period $K^{\prime}$, subject to the following budget constraint:

$$
q(\mathbf{Z}) K^{\prime}=N+B_{f}+B_{I} .
$$

As in Gertler and Kiyotaki (2010), we assume incomplete market in that banks can only borrow from households on a risk-free account. ${ }^{10}$ In our model, the total amount of capital for the next period, $K^{\prime}$ is determined at the end of the current period before the realization of shocks of the next period. That is, we assume one period time to plan as in standard real business cycle models. However, different from the standard representative firm setup, capital can be reallocated across firms after idiosyncratic productivity shocks are realized, which we turn to next.

\footnotetext{
${ }^{9}$ See Gertler and Kiyotaki (2010) for details.

${ }^{10}$ With a slight abuse of notation, we use $B_{f}$ as both the amount of saving of the household and the amount of borrowing of the bank. We do so to save notation, because market clearing requires that the demand and supply of bank loans must equal.
} 
The market for capital reallocation opens after the realization of aggregate productivity shock $A^{\prime}$, and idiosyncratic productivity shock $a^{\prime}$. Let $Q\left(\mathbf{Z}^{\prime}\right)$ denote the price of capital on the capital reallocation market in state $\mathbf{Z}^{\prime}$, and let $Q_{j}\left(\mathbf{Z}^{\prime}\right)$ denote the price of capital on an island with idiosyncratic productivity shock $a_{j}$ for $j=H, L$, in aggregate state $\mathbf{Z}^{\prime}$. Here, without loss of generality, we use $j=H, L$ to denote both the realization of the idiosyncratic productivity shock and the intermediary on the island whose current period idiosyncratic productivity is $a_{j}{ }^{11}$ We use $R A_{j}\left(\mathbf{Z}^{\prime}\right)$ denote the total amount of capital purchased on the reallocation market by intermediary $j$ in state $\mathbf{Z}^{\prime}$. The total net worth of intermediary $j$ at the end of the next period after the repayment of household loan and interbank borrowing is:

$$
N_{j}^{\prime}=Q_{j}\left(\mathbf{Z}^{\prime}\right)\left[K^{\prime}+R A_{j}\left(\mathbf{Z}^{\prime}\right)\right]-Q\left(\mathbf{Z}^{\prime}\right) R A_{j}\left(\mathbf{Z}^{\prime}\right)-R_{f}(\mathbf{Z}) B_{f}-R_{I}(\mathbf{Z}) B_{I} \cdot{ }^{12}
$$

Here we allow $Q\left(\mathbf{Z}^{\prime}\right), Q_{H}\left(\mathbf{Z}^{\prime}\right)$ and $Q_{L}\left(\mathbf{Z}^{\prime}\right)$ to be potentially different because limited commitment of financial contracts may prevent the marginal product of capital be equalized to the price of capital on the reallocation market when the constraint is binding. The interpretation of (11) is that at the end of the next period, the total value of capital on island $j$, including the capital purchased in the current period, $K^{\prime}$ and the capital obtained on the reallocation market, $R A_{j}\left(\mathbf{Z}^{\prime}\right)$, is $Q_{j}\left(\mathbf{Z}^{\prime}\right)\left[K^{\prime}+R A_{j}\left(\mathbf{Z}^{\prime}\right)\right]$. The intermediary also needs to pay back the cost of capital obtained on the reallocation market, $Q\left(\mathbf{Z}^{\prime}\right) R A_{j}\left(\mathbf{Z}^{\prime}\right)$, and one-period risk-free loans borrowed from the household and other banks, $B_{f}$, and $B_{I}$.

Note that capital on the reallocation market can only be purchased by issuing a within period interbank loan. This is because the purchase of capital on the reallocation market happens before production and the receipt of payment from local firms, $Q_{j}\left(\mathbf{Z}^{\prime}\right)\left[K^{\prime}+R A_{j}\left(\mathbf{Z}^{\prime}\right)\right]$. Figure 7 illustrates the time of events in period $t$ and period $t+1$. At the end of period $t$, the household has total disposable income $W$ and the total net worth of the intermediary sector is $N$. The household wealth is allocated between consumption in the current period, $C$ and a risk-free deposit with the banks, $B_{f}$. From the bank's perspective, the total net worth and the total consumer loans, $B_{f}$ are used to purchase capital at price $q$. At the end of period $t$, a typical bank purchased $K^{\prime}$ amount of capital for period $t+1$ production before the realization of the productivity shocks in $t+1$.

Period $t+1$ is divided into four subperiods. In the first subperiod, the aggregate pro-

\footnotetext{
${ }^{11}$ As we show later in the paper, prices and allocation depend only on the aggregate state variable $\mathbf{Z}$, and the current period idiosyncratic productivity shock $a$.

${ }^{12}$ We allow $R A\left(\mathbf{Z}^{\prime}, a^{\prime}\right)$ to be negative. In fact, market clearing implies that the sum of $R A\left(\mathbf{Z}^{\prime}, a^{\prime}\right)$ across all banks must equal zero.
} 
ductivity shock $A^{\prime}$ and the idiosyncratic productivity shock, $a^{\prime}$ are realized and the capital reallocation market opens. Banks on the high (idiosyncratic) productivity islands have an incentive to purchase more capital on the reallocation market and banks on the low productivity islands have an incentive to sell. Note that transactions on the capital reallocation market must be done by issuing interbank credit, because at this point production has not begun and banks has not receive payment from firms yet. Production happens in the second subperiod, and firms pay back the cost of capital to local banks at the end of the second subperiod.

In the third subperiod, banks payback their interbank loans and household deposit. Importantly, after banks receive payment from local firms and before they pay back loans to creditors, banks have an opportunity to default. Upon default, bankers can abscond with a fraction of their assets, and set up a new bank to operate on some other island. We assume that the amount of asset bankers can abscond with upon default is:

$$
\theta Q_{j}\left(\mathbf{Z}^{\prime}\right)\left[K^{\prime}+R A_{j}\left(\mathbf{Z}^{\prime}\right)\right]-\omega\left[Q(\mathbf{Z}) R A_{j}\left(\mathbf{Z}^{\prime}\right)+R_{I}(\mathbf{Z}) B_{I}\right]
$$

The total amount of capital on the island is $\left[K^{\prime}+R A_{j}\left(\mathbf{Z}^{\prime}\right)\right]$, where $R A_{j}\left(\mathbf{Z}^{\prime}\right)$ is purchase on the capital reallocation market under within-period interbank loan. Upon default, bankers take away all of the capital on the island, but they can only sell a fraction $\theta$ of them on the market. Therefore, upon default, the total receipt of bankers on island $j$ is $\theta Q_{j}\left(\mathbf{Z}^{\prime}\right)\left[K^{\prime}+R A_{j}\left(\mathbf{Z}^{\prime}\right)\right]$. The amount $\theta Q_{j}\left(\mathbf{Z}^{\prime}\right)\left[K^{\prime}+R A_{j}\left(\mathbf{Z}^{\prime}\right)\right]$ can be viewed as the deadweight loss associated with bankruptcy. Similar to Gertler and Kiyotaki (2010), we assume that bankers have a better technology to enforce contracts then households. This captured by the parameter $\omega \in[0, \theta]$. The interpretation is that in the event of default, a fraction $\omega$ of interbank borrowing can be recovered. The case $\omega=0$ means banks are no better than households in enforcing contracts, and $\omega=1$ corresponds to the case of frictionless interbank market. The possibility of default implies that the contracting between borrowing and lending banks must respect the following limited enforcement constraint:

$$
N_{j}^{\prime} \geq \theta Q_{j}\left(\mathbf{Z}^{\prime}\right)\left[K^{\prime}+R A_{j}\left(\mathbf{Z}^{\prime}\right)\right]-\omega\left[Q(\mathbf{Z}) R A_{j}\left(\mathbf{Z}^{\prime}\right)+R_{I}(\mathbf{Z}) B_{I}\right], \quad \forall \mathbf{Z}^{\prime} \text { and } \forall j
$$

where $N^{\prime}$ is given by (11). Inequality (13) is the incentive compatibility constraint for banks. It implies that anticipating the possibility of default, lending banks will make sure that the borrowing bankers do not have the incentive to default on loan in all possible states of the world. 
In the last subperiod, bankers clear their interbank transactions and consumers receive dividend payment from banks and firms, risk-free return from bank deposit and make their consumption and saving decisions. At this point, as in Gertler and Kiyotaki (2010), bank net worth is allowed to move freely across islands. This implies that the expected return on all islands are equalized and the therefore the ratio of bank net worth to capital must be equalized across all island as well. This assumption is made so that the distribution of bank net worth is not a state variable in the construction of the equilibrium. The heterogeneity in the realization of idiosyncratic productivity shocks motivates the need for capital reallocation, and the possibility of moving bank net worth across islands implies the existence of a representative bank and makes it possible to obtain global solutions of the model which is important for the analysis of counter-cyclical volatility.

We note that no arbitrage on the capital markets within an island implies that

$$
Q_{j}\left(\mathbf{Z}^{\prime}\right)=M P K_{j}\left(\mathbf{Z}^{\prime}\right)-H_{K}\left(I^{\prime}, K^{\prime}\right)+(1-\delta) q\left(\mathbf{Z}^{\prime}\right)
$$

The interpretation is that one unit of capital on island $j$ produces an additional current period output $M P K_{j}\left(\mathbf{Z}^{\prime}\right)$, lowers the total cost of producing new investment by $H_{K}\left(I^{\prime}, K^{\prime}\right)$, and depreciates at rate $\delta$ per period. In a frictionless market the above condition and the fact $Q_{j}\left(\mathbf{Z}^{\prime}\right)=Q\left(\mathbf{Z}^{\prime}\right)$ for all $j$ guarantees that the marginal product of capital must be equalized across all islands. In our model, misallocation may happen in equilibrium due to limited enforcement of financial contracts.

As in Gertler and Kiyotaki (2010), a fraction $\lambda$ of bank's net worth is forced to be liquidated and paid back to the household as dividend. This assumption is maintained to insure that banks do not save out of their financing constraints in the long run. Because bank net worth can be freely moved across islands at the end of every period, the value function and decision rules of banks must be linear in $N$. This feature of the model greatly simplifies our analysis, because given the total net worth of the entire banking sector, the equilibrium does not depend on the distribution of bank net worth across islands. We denote the value function of banks as $\mu(\mathbf{Z}) N$. A typical bank maximizes:

$$
\mu(\mathbf{Z}) N=\max _{B_{f}, K^{\prime}\left\{R A_{j}\left(\mathbf{Z}^{\prime}\right)\right\}_{\mathbf{Z}^{\prime}, j}} E\left[M^{\prime}\left\{\lambda N^{\prime}+(1-\lambda) \mu\left(\mathbf{Z}^{\prime}\right) N^{\prime}\right\} \mid \mathbf{Z}\right]
$$

by choosing total capital stock for the next period, $K^{\prime}$, total borrowing from households, $R_{f}$, and a state-contingent plan for capital reallocation, $R A_{j}\left(\mathbf{Z}^{\prime}\right)$ for all possible realizations of 
$\mathbf{Z}^{\prime}$ and $j$, subject to constraints (10), (11), and (13).

Two important distinctions between our model and Gertler and Kiyotaki (2010) are the heterogeneity in productivity across firms and the fact that the market for capital reallocation and interbank borrowing opens after productivity shocks realize and before production. In our benchmark calibration, we assume that $\theta$ follows a Markov chain with state space $\left[\theta_{L}, \theta_{H}\right]$. Increases in $\theta$ raise banks' outside options and lower their borrowing capacity whenever the limited enforcement constraint (13) binds. We interpret shocks to $\theta$ as shocks to the

severity of the agency frictions and we are interested in the equilibrium mechanism through which these shocks translates into capital misallocation and fluctuations of macroeconomic quantities.

We make one more assumption on the productivity $A$. We assume $A_{t}=\bar{A}_{t} K_{t}^{1-\alpha}$, where $\bar{A}_{t}$ is a Markov process of exogenous productivity shocks. This specification follows Frankel (1962) and Romer (1986) and is a parsimonious way to inject endogenous growth into the model. From an asset pricing perspective, this allows shocks to affect long-run growth rates and generate significant risk premium on equity. From a technical point of view, as we will see in Section $\mathrm{V}$ of the paper, this allows us to reduce one state variable in the construction of the Markov equilibrium.

\section{Market Clearing}

Because market clearing conditions have to hold in every period, we suppress the dependence of all variables on time or state variables in this section to save notation.

As in standard neoclassical models, there is one period time to plan in the capital accumulation technology. The total amount of capital used for production in the next period, denoted $K^{\prime}$ is determined at the end of the current period and equals to the total amount of capital used in the current period after depreciation plus the total amount of new investment made in the current period:

$$
K^{\prime}=(1-\delta) K+I
$$

Here we use the fact of the existence of a representative bank, and we use the notation $K$ and $K^{\prime}$ for both the capital stock of the whole economy and for the capital stock held in a typical (representative) bank.

The total amount of capital used on any island must equal the amount of capital the bank purchased in the last period plus the amount of capital purchased on the capital reallocation 
market:

$$
k_{j}=K+R A_{j}, \text { for } j=H, L .
$$

Here, to save notation, we use the fact that we can without loss of generality assume that prices and allocations depends only on the aggregate state variable and the realization of the current period productivity shocks (but not on the history of the realization of idiosyncratic productivity shocks).

In addition, the total amount of interbank borrowing in the economy must be zero,

$$
B_{I}=0
$$

Because banks are ex ante identical before the realization of idiosyncratic productivity shocks, $B_{I}=0$. The possibility of interbank bank borrowing on the intertemporal bank loan market does not affect allocation but determines the interbank borrowing rate, an object that can be measured empirically and used to discipline our quantitative exercise. Also, the total amount of capital used for production is less than or equal to the total amount of capital available:

$$
\pi\left(K+R A_{H}\right)+(1-\pi)\left(K+R A_{L}\right) \leq K .
$$

The term $K+R A_{H}$ is the total amount capital used in high-productivity firms, and $K+R A_{L}$ is the total amount of capital used in low productivity firms. It is important to note that we use the weak inequality in the above resource constraint. In a frictionless economy, because preferences are monotone, inequality (18) always hold with equality. However, in our economy with agency frictions, (18) may hold with strictly inequality when banks on all islands are constrained.

We assume that labor is perfectly mobile and aggregate labor supply is normalized to 1. The market clearing condition for labor is

$$
\pi l_{H}+(1-\pi) l_{L}=1
$$

Market clearing for final goods requires that total consumption and cost of investment sum up to total output:

$$
C+H(I, K)=Y,
$$

where $H(I, K)$ is the adjustment cost function defined in (8), and $K$ is the total amount of capital in the economy. 


\section{E Markov Equilibrium}

Let $N_{H}^{\prime}$ denote the total amount of net worth on all high-productivity islands at the beginning of the next period, and let $N_{L}^{\prime}$ denote the total amount of net worth on all low productivity islands at the beginning of the next period. The total amount of net worth in the banking sector in the next period is:

$$
N^{\prime}=(1-\lambda)\left\{\pi N_{H}^{\prime}+(1-\pi) N_{L}^{\prime}\right\}+\chi q\left(\mathbf{Z}^{\prime}\right) K^{\prime} .
$$

As we explained before, in every period, a $\lambda$ fraction of bank net worth is forced to liquidate and paid back to the household. This assumption is needed so that banks do not saving out of the limited commitment constraint in the long run. From the economics point of view, this can be interpreted as bankers having a shorter horizon than the representative agent. We also assume that additional net worth is injected into the banking sector every period. We assume that this amount is $\chi q\left(\mathbf{Z}^{\prime}\right) K^{\prime}$, where $\chi$ is a parameter that controls the rate of injection. As in Gertler and Kiyotaki (2010), this assumption is maintained to prevent bank net worth from being depleted in the long-run.

Using the law of motion of bank net worth in equation (11), and banks' balance sheet constraint, (10), the law of motion of the total net worth in the banking sector, denoted $N$ can be written as

$$
N^{\prime}=(1-\lambda)\left\{\int Q_{j}\left(\mathbf{Z}^{\prime}\right)\left[K^{\prime}+R A_{j}\left(\mathbf{Z}^{\prime}\right)\right] d j-R_{f}(\mathbf{Z})\left[q(\mathbf{Z}) K^{\prime}-N\right]\right\}+\chi q\left(\mathbf{Z}^{\prime}\right) K^{\prime} .
$$

A Markov equilibrium is a set of prices and quantities and the law of motion of the state variable $\mathbf{Z}$ (to be specified) such that household maximizes utility, non-financial firms and financial intermediaries maximizes their profit and all markets clear. We provide a construction of the state variables and the Markov equilibrium in Section IV of the paper.

\section{A Two-Period Version of the Model}

In this section, we explicitly solve a two-period version of the above model and use this simple setup to illustrate the main intuition of the fully dynamic model. We make sevel simplifying assumptions. First, we assume that capital share $\alpha=1$, that is, capital is the

only input and the production technology is linear. Second, we also assume that there is no adjustment cost, $h=0$. Third, $\omega=0$, that is, banks are no better than households in 
reinforcing interbank loans. Fourth, the representative agent has log preferences. Finally, the only source of uncertainty in this economy is aggregate productivity, $A_{1}$, which can take on two values, $A_{H}$ and $A_{L}$, where $A_{H}>A_{L}$. We will call state $A_{H}$ booms and $A_{L}$ recessions.

Under the above assumptions, the household's maximization problem is written as:

$$
\begin{aligned}
& \max \ln C_{0}+\beta E\left[\ln C_{1}\left(A_{1}\right)\right] \\
\text { subject to }: & C_{0}+B_{f}=W_{0} \\
C_{1}\left(A_{1}\right)= & R_{f} B_{f}+D_{F, 1}\left(A_{1}\right)+N_{1}\left(A_{1}\right) .
\end{aligned}
$$

Here, because there are only two periods, total bank net worth in period one, $N_{1}\left(A_{1}\right)=$ $\pi N_{H, 1}\left(A_{1}\right)+(1-\pi) N_{L, 1}\left(A_{1}\right)$ is fully paid back to the household. Households' budget constraint is greatly simplified because in the absence of adjustment cost, the profit of investment goods producer is zero, and under the assumption of $\alpha=1$, there is no labor income. In addition, there is no injection of net worth from the household to the banking sector in the two period model. The notation $C_{1}\left(A_{1}\right)$ emphasizes the dependence of quantities (in this case, consumption) on the realization of the productivity shock in period one, $A_{1}$.

Note that in a two period model, because capital is valueless at the end of the period, the price of capital in the second period before production, $Q_{j}=M P K_{j}$, for $j=H, L$. Under these assumptions, the bank's maximization problem can be written as

$$
\begin{gathered}
\max _{B_{f}, K^{\prime},\left\{R A_{H}\left(A_{1}\right), R A_{L}\left(A_{1}\right)\right\}_{A_{1}}} E\left[M\left\{\pi N_{H, 1}\left(A_{1}\right)+(1-\pi) N_{L, 1}\left(A_{1}\right)\right\}\right] \\
K_{1}=N_{0}+B_{f} \\
N_{H, 1}\left(A_{1}\right)=Q_{H}\left(A_{1}\right)\left[K_{1}+R A_{H}\left(A_{1}\right)\right]-Q\left(A_{1}\right) R A_{H}\left(A_{1}\right)-R_{f} B_{f} \\
N_{L, 1}\left(A_{1}\right)=Q_{L}\left(A_{1}\right)\left[K_{1}+R A_{L}\left(A_{1}\right)\right]-Q\left(A_{1}\right) R A_{L}\left(A_{1}\right)-R_{f} B_{f} \\
N_{H, 1}\left(A_{1}\right) \geq \theta Q_{H}\left(A_{1}\right)\left[K_{1}+R A_{H}\left(A_{1}\right)\right] \text { for all } A_{1}, \\
N_{L, 1}\left(A_{1}\right) \geq \theta Q_{L}\left(A_{1}\right)\left[K_{1}+R A_{L}\left(A_{1}\right)\right] \quad \text { for all } A_{1} .
\end{gathered}
$$

In the above optimization problem, $M=\beta \frac{C_{0}}{C_{1}}$ is the stochastic discount factor implied by household consumption. $N_{H, 1}$ is bank net worth in period one in the case $a_{1}=a_{H}$, and $N_{L, 1}$ is bank net worth in period one in the case $a_{1}=a_{L}$.

For simplicity, we also assume that there is no financial friction in period 0 , and total output in this period is given by $A_{0} K_{0}$, where $A_{0}$ is the aggregate productivity in the first 
period. It is convenient to define

$$
\phi=\frac{K_{1}+R A_{H}}{K_{1}+R A_{L}} .
$$

as the ratio of capital on high productivity islands with respect to that on low productivity islands. We denote $\hat{\phi}=\left(\frac{a_{H}}{a_{L}}\right)^{\eta-1}$ to be the optimal ratio of $\frac{K_{H}}{K_{L}}$ that equalizes the marginal product of capital across all islands. We also denote

$$
\rho=\frac{\pi\left(K_{1}+R A_{H}\right)+(1-\pi)\left(K_{1}+R A_{L}\right)}{K_{1}}
$$

to be the capital utilization rate in period 1. In our notation, $\phi$ and $\rho$ are measures of misallocation. $\phi$ measures how efficient capital reallocation is across productive firms, and $\rho<1$ indicate an extreme form of capital misallocation: some capital is not used for production at all. Total output and marginal product of capital can be written as functions of $\phi$ and $\rho$, which we summarize in the following proposition.

Proposition 1 (Aggregation of the Product Market)

The total output of the economy is given by

$$
Y=A \rho f(\phi) \bar{K}^{\alpha},
$$

where the function $f:[1, \hat{\phi}] \rightarrow[0,1]$ is defined as:

$$
f(\phi)=\frac{\left(\pi \hat{\phi}^{1-\xi} \phi^{\xi}+1-\pi\right)^{\frac{\alpha}{\xi}}}{(\pi \phi+1-\pi)^{\alpha}(\pi \hat{\phi}+1-\pi)^{\frac{\alpha}{\xi}-\alpha}}
$$

The marginal product of capital on low productivity islands, denoted $M P K_{L}$ and the marginal product of capital on high productivity island, denoted $M P K_{H}$ can be written as:

$$
\begin{aligned}
M P K_{L}(A, \phi) & =\alpha\left(1-\frac{1}{\eta}\right)\left(\frac{A}{\bar{K}}\right)^{1-\alpha} f(\phi) \frac{\pi \phi+1-\pi}{\pi \hat{\phi}^{1-\xi} \phi^{\xi}+1-\pi}, \\
M P K_{H}(A, \phi) & =M P K_{L}(A, \phi)\left(\frac{\hat{\phi}}{\phi}\right)^{1-\xi},
\end{aligned}
$$

where the parameter $\xi \in(0,1)$ is defined as $\xi=\frac{\alpha \eta-\alpha}{\alpha \theta-\alpha+1}$.

Proof. See Appendix B. 
Note that the function $\rho f(\phi)$ is a measure of misallocation. It is straightforward to show that $f$ is strictly increasing with $f(\hat{\phi})=1$. The case $\rho=1$ and $\phi=\hat{\phi}$ is the first best scenario with maximum amount of capital reallocation. In general, $\rho f(\phi) \leq 1$ and misallocation happens when strict inequality holds. When $\rho=1$ and $\phi=\hat{\phi}$ the aggregate production function becomes the standard Cobb-Douglas case, and the marginal product of capital on all islands equalizes according to equations (30) and (31). In general, $M P K_{H}(\phi)>$ $M P K_{L}(\phi)$ for $\phi \in(1, \hat{\phi})$.

Because we have assumed that the technology is $\operatorname{AK}(\alpha=1)$, equilibrium quantities are homogenous of degree one in $K_{0}$ and prices are homogenous of degree zero. We define $n=\frac{N_{0}}{K_{0}}$ and the equilibriums can be indexed by $n$.

\section{Proposition 2 (Capital Misallocation)}

There exist cut-off values $\bar{n}, \hat{n}$, and $n^{*}$ such that $0<\bar{n}<\hat{n}<n^{*}$ and

1. For all $n \geq n^{*}$, none of the limited enforcement constraints, (26) or (27) binds. In this case, there is no misallocation, and the marginal product of capital is equalized across all islands: $Q_{H}(A)=Q_{L}(A)=Q(A)=M P K_{H}(A, \hat{\phi})$.

2. For $n \in\left[\hat{n}, n^{*}\right)$, none of the limited enforcement constraints binds in booms when $A_{1}=A_{H}$. In recessions when $A_{1}=A_{L}$, (26) binds but (27) does not. In this case, misallocation happens only in recessions and $Q_{H}\left(A_{L}\right)>Q\left(A_{L}\right)=Q_{L}\left(A_{L}\right)$.

3. For $n \in[\bar{n}, \hat{n})$, the limited enforcement constraint for banks on high productivity islands, (26) binds at all times, but the limited enforcement constraint for banks on low productivity islands, (27) never binds. In this case, misallocation happens for all realizations of $A_{1}$ and $Q_{H}\left(A_{1}\right)>Q\left(A_{1}\right)=Q_{L}\left(A_{1}\right)$.

4. For $n \in(0, \bar{n})$, (26) binds at all times. Condition (27) holds with equality in recessions but not in booms. In this case, misallocation happens for all realizations of $A_{1}$ and $Q_{H}\left(A_{1}\right)>Q\left(A_{1}\right)=Q_{L}\left(A_{1}\right)$. In addition, under utilization occurs in recessions: $\rho\left(A_{L}\right)<1$.

\section{Proof. See Appendix.}

By the above proposition, $\bar{n}, \hat{n}$ and $n^{*}$ divide the state space into four regions. For $n \geq n^{*}$, none of the financing constraints bind, and the marginal product of capital are equalized across all islands. In this case, there is no misallocation regardless of the realization of the aggregate productivity shock. 
For $\hat{n} \leq n<n^{*}$, the financing constraint on high productivity islands binds, but only in recessions. In this case, $Q_{H}\left(A_{H}\right)=Q\left(A_{H}\right)=Q_{L}\left(A_{H}\right)$ and there is no misallocation in booms. However, $Q_{H}\left(A_{L}\right)>Q\left(A_{L}\right)=Q_{L}\left(A_{L}\right)$ and misallocation occurs in recessions. In this case, banks who finance for high productivity firms are constrained in bad times. In recessions, it is profitable for banks on high productivity islands to purchase more capital, as the marginal product of capital on high productivity islands is higher than the price of capital. However, they are not able to finance the efficient amount capital reallocation because they do not have enough net worth to collateralize inter-bank loans. On the other hand, $Q(A)=Q_{L}(A)$ for all $A$ and banks on low productivity islands are not constrained. The marginal product of capital on low productivity islands equals the market price of capital. In this region, limited enforcement constrains cross-sectional capital reallocation only in bad times when aggregate productivity is low.

For $\bar{n} \leq n<\hat{n}$, banks on high productivity islands are constrained in both booms and recessions, and $Q_{H}(A)>Q_{L}(A)=Q(A)$ at all times. However, the limited enforcement constraint for banks on low productivity island never binds. As before, banks on high productivity islands are more likely to be constrained. Note that as long as $n \geq \bar{n}$, the constraint (27) never binds and capital utilization is $100 \%$.

In the region, $n<\bar{n}$, banks on high productivity islands are constrained and misallocation of capital occurs at all times. In addition, in recessions, constraint (27) for banks on low productivity islands binds in recessions and this is precisely when capital utilization drops below 1. To summarize, both constraints (26) and (27) are more likely to bind in recessions. Misallocation occurs whenever constraint (26) binds, and constraint (27) is associated with an extreme form of misallocation: capital under utilization.

We illustrate the intuition for the above proposition using Figures 8-11. In Figure 8, we plot measures of misallocation as a function of bank net worth. In the top panel, we plot total output in booms (dotted line) and recessions (dashed line) as a function of bank net worth. Note that total output in general depends on bank net worth. Misallocation affects output in booms only for values of $n$ less than $\hat{n}$. However, quantitatively, the effect of misallocation is small under our parameter values. Misallocation is much more likely to occur in recessions, and its effect is much stronger. The middle panel plots $f(\phi)$ as a function of net worth. It is clear that misallocation is much more pronounced in recessions. In the bottom panel of Figure 8, we plot the total measure of misallocation, $\rho f(\phi)$ as a function of bank net worth. Quantitatively, the effect of capital under-utilization is much stronger than the effect of misallocation across islands. When $n<\bar{n}$, misallocation occurs in recessions, 
and total output drops sharply. We make two observations here. First, under-utilization of capital never happens in booms. It is never optimal for the economy to accumulate so much capital that it will be under-utilized in all states of the world. Even if banks net worth is very low, under-utilization does not occur in booms because it is more efficient to reduce investment than build overcapacity that will never be utilized. Second, the behavior of the model is very different in the region where both constraints are binding and under-utilization occurs. This type of nonlinearity also occurs in the models of Brunnermeier and Sannikov (2014) and He and Krishnamurthy (2014).

We plot the investment rate(top panel) and bank leverage (bottom panel) as functions of bank net worth in Figure 9. Note that investment is an increasing function of intermediary net worth and leverage is a decreasing function. When banks are under-capitalized, investment drops as a result of the lower financing capacity of the intermediary sector. As the same time, borrowing increases and leverage ratio rises. As He and Krishnamurthy (2014), our model implies countercyclical leverage of the intermediary sector.

Figure 10 plots the average output (top panel) and the volatility of output (bottom panel) as a function of bank networth. Clearly, average output increases with bank net worth because lower bank net worth reduces the efficiency of capital reallocation and lowers output, especially in recessions. The bottom panel shows an important property of the volatility of output in our model: it is decreasing in bank net worth. Lower levels of bank net worth is associated with higher leverage and stronger amplification effects in general. Especially when net worth is lower than $\bar{n}$, in this region a negative productivity shock is associated with an extremely form of capital misallocation: capital under-utilization. As a result, volatility increase sharply. This region can be interpreted as the crisis region, where the level of output drops sharply and the volatility of the economy increases dramatically with adverse productivity shocks.

In Figure 11, we plot the total amount of capital reallocation as a function of normalized bank net worth (top panel) and the cross-sectional dispersion of log marginal product of capital as a function of normalized bank net worth (bottom panel). The dashed line stands for booms are the dotted line are recessions. Clearly, the quantity of capital reallocation is increasing bank net worth and aggregate productivity shocks. In the bottom panel, we plot the cross-sectional variance of log marginal product of capital. Note here, we do not account for capital under-utilization. Because the marginal product of unutilized capital is zero, the cross-sectional variance would be infinite in the region $n<\bar{n}$ if we account for under-utilization. Overall, the implications of our model is consistent with evidence in 
Eisfeldt and Rampini (2006) that the quantity of capital reallocation is pro-cyclical and the benefit of capital reallocation is counter-cyclical.

\section{Construction of the Markov Equilibrium}

Because of the financing constraints, the equilibrium does not have a planner representation. Therefore the standard construction of recursive equilibrium (for example, Stokey and Lucas (1989), Ljungqvist and Sargent (2004)) does not apply in our model. In this section, we construct a Markov equilibrium of the economy described in Section III of the paper as the fixed point of a vector of equilibrium functionals. In particular, we conjecture that a Markov

equilibrium exists with state variable $\mathbf{Z}=(\phi, \theta, n)$, where $\phi$ is the current level of $\frac{K_{H}}{K_{L}}, \theta$ is the parameter of bankers' outside options, $n$ is total net worth normalized by current period total capital stock $K$. To motivate some of details of the equilibrium construction, we first make several observations. Let $\zeta_{H}$ denote the Larangian multiplier of the constraint (13) for high productivity banks and $\zeta_{L}$ be the Lagrangian multiplier for the same constraint with $a=a_{L}$. The first order condition with respect to banks' choice of $B_{f}$ imply:

$$
E\left[\tilde{M}^{\prime}\left\{1+\zeta_{H}\left(\mathbf{Z}^{\prime}\right)+\zeta_{L}\left(\mathbf{Z}^{\prime}\right)\right\} \mid \mathbf{Z}\right] R_{f}(\mathbf{Z})=\frac{1}{q(\mathbf{Z})} E\left[\tilde{M}^{\prime}\left\{1+\zeta_{H}\left(\mathbf{Z}^{\prime}\right)+\zeta_{L}\left(\mathbf{Z}^{\prime}\right)\right\} Q\left(\mathbf{Z}^{\prime}\right) \mid \mathbf{Z}\right]
$$

where given the expression of $M^{\prime}$ in (9), $\tilde{M}^{\prime}$ is defined by:

$$
\tilde{M}^{\prime}=M^{\prime}\left\{\lambda+(1-\lambda) \mu\left(\mathbf{Z}^{\prime}\right)\right\}
$$

The Lagrangain multipliers must satisfy:

$$
\begin{aligned}
\pi\left[M P K_{H}\left(\phi^{\prime}\right)-M P K_{L}\left(\phi^{\prime}\right)\right] & =\zeta_{H}\left(\mathbf{Z}^{\prime}\right) O\left(\mathbf{Z}^{\prime}\right), \\
(1-\pi)\left[M P K_{H}\left(\phi^{\prime}\right)-M P K_{L}\left(\phi^{\prime}\right)\right] & =\zeta_{L}\left(\mathbf{Z}^{\prime}\right) O\left(\mathbf{Z}^{\prime}\right) .
\end{aligned}
$$

where we denote

$$
O\left(\mathbf{Z}^{\prime}\right)=(1-\omega) Q\left(\mathbf{Z}^{\prime}\right)-\left[1-\delta-\theta^{\prime}\right] q\left(\mathbf{Z}^{\prime}\right)
$$


and the marginal product of capital are functions of $\phi$ :

$$
\begin{aligned}
& M P K_{L}(\phi)=\alpha\left(1-\frac{1}{\eta}\right) \bar{A} f(\phi) \frac{\pi \phi+1-\pi}{\pi \hat{\phi}^{1-\xi} \phi^{\xi}+1-\pi} \\
& \operatorname{MPK}_{H}(\phi)=\alpha\left(1-\frac{1}{\eta}\right) \bar{A} f(\phi) \frac{\pi \phi+1-\pi}{\pi \hat{\phi}^{1-\xi} \phi^{\xi}+1-\pi}\left(\frac{\hat{\phi}}{\phi}\right)^{1-\xi} .
\end{aligned}
$$

Intuitively, optimality requires that banks must be indifferent between borrowing from the risk-free rate $R_{f}(\mathbf{Z})$ and purchasing an additional capital, $K^{\prime}$. The left hand side of (32) is the marginal cost of borrowing, and the right hand side of the same equation is the marginal benefit of investing in capital. The current-period price of capital is $q(\mathbf{Z})$, investing in an additional unit of capital saves the bank $Q\left(\mathbf{Z}^{\prime}\right)$ in the next period as $Q\left(\mathbf{Z}^{\prime}\right)$ is the unit price of capital in the reallocation market. In addition, it relaxes the limited enforcement constraints, the benefit of which are measured by $\zeta_{H}$ and $\zeta_{L}$, respectively.

The first order condition on the choice of interbank risk-free loan implies

$$
E\left[\tilde{M}^{\prime}\left\{1+(1-\omega) \zeta\left(\mathbf{Z}^{\prime}\right)\right\}\right] R_{I}(\mathbf{Z})=E\left[\tilde{M}\left\{1+\zeta\left(\mathbf{Z}^{\prime}\right)\right\}\right] R_{f}(\mathbf{Z})
$$

The envelope condition implies that $\mu(\mathbf{Z})$ must satisfy:

$$
\mu(\mathbf{Z})=E\left[\tilde{M}^{\prime}\left\{1+\zeta_{H}\left(\mathbf{Z}^{\prime}\right)+\zeta_{L}\left(\mathbf{Z}^{\prime}\right)\right\}\right] R_{f}(\mathbf{Z}) .
$$

Given the convexity nature of the optimization problems of banks, households and firms, the above first order conditions and the constraints are equivalent to optimality. These conditions can then be used to construct the equilibrium. We use lower case to denote equilibrium quantities normalized by total capital stock, for example, $c=\frac{C}{K}, b_{f}=\frac{B_{f}}{K}$, $n=\frac{N}{K}$ stands for household consumption, household investment in the risk-free bond, and bank net worth normalized by current period capital stock. Below we describe a procedure to construct a Markov equilibrium with state space $\mathcal{Z}=[1, \hat{\phi}] \otimes\left[\theta_{L}, \theta_{H}\right] \otimes(0, \infty)$, where $[1, \hat{\phi}]$ is the set of feasible values of $\phi,\left[\theta_{L}, \theta_{H}\right]$ is the set of possible values of $\theta$ and $(0, \infty)$ is set of possible realizations of $n$.

We construct the Markov equilibrium by starting with an initial guess of a set of equilibrium functionals, $\{c(\mathbf{Z}), v(\mathbf{Z}), q(\mathbf{Z}), \mu(\mathbf{Z})\}_{\mathbf{Z} \in \mathcal{Z}}$. Assuming the initial guess $c\left(\mathbf{Z}^{\prime}\right), v\left(\mathbf{Z}^{\prime}\right)$, $q\left(\mathbf{Z}^{\prime}\right), \mu\left(\mathbf{Z}^{\prime}\right)$ is part of the equilibrium prices and quantities in the next period. We use the optimality conditions and the constraints to construct the policy functions of household, 
banks, and firms, including household consumption, price of capital, and the value function of the bank, which we denote as $\{T c(\mathbf{Z}), T v(\mathbf{Z}), T q(\mathbf{Z}), T \mu(\mathbf{Z})\}_{\mathbf{Z} \in \mathcal{Z}}$. The equilibrium functional is the fixed point where $T[c, v, q, \mu]=[c, v, q, \mu]$. We show that any fixed point of the $T$ operator constitute a Markov equilibrium in the sense that a Markov equilibrium defined in Section II can be constructed from the equilibrium functional. This construction also provides a recursive method that can be used to solve the equilibrium numerically, which we detail in Appendix D.

Given the equilibrium functional, $\{c(\mathbf{Z}), v(\mathbf{Z}), q(\mathbf{Z}), \mu(\mathbf{Z})\}_{Z \in \mathcal{Z}}$, suppose that there exists a vector of policy functions,

$\left\{T c(\mathbf{Z}), T v(\mathbf{Z}), T q(\mathbf{Z}), T \mu(\mathbf{Z}), i(\mathbf{Z}), b_{f}(\mathbf{Z}),\left[\zeta_{H}(\mathbf{Z}, \boldsymbol{\theta}), \zeta_{L}(\mathbf{Z}, \theta), \phi(\mathbf{Z}, \theta), Q(\mathbf{Z}, \theta)\right]_{\theta \in\left[\theta_{L}, \theta_{H}\right]}\right\}_{\mathbf{Z} \in \mathcal{Z}}$

such that conditions 1-8 below are met. We first define the law of motion of the state variables using the equilibrium functionals and policy functions. For each possible realization of the aggregate productivity shock, $\theta^{\prime}$, the law of motion of the state variable $n$ is given by:

$$
\begin{aligned}
n\left(\mathbf{Z}, \theta^{\prime}\right)= & \left.(1-\lambda) \alpha\left(1-\frac{1}{\eta}\right) \bar{A} f\left(\phi\left(\mathbf{Z}, \theta^{\prime}\right)\right)-(1-\lambda) R_{f}(\mathbf{Z})\left[q(\mathbf{Z})-\frac{n}{1-\delta+i(\mathbf{Z})}\right] 40\right) \\
& +[(1-\lambda)(1-\delta)+\chi] q\left(\phi\left(\mathbf{Z}, \theta^{\prime}\right), \theta^{\prime}, n\left(\mathbf{Z}, \theta^{\prime}\right)\right)
\end{aligned}
$$

where the interest rate $R_{f}(\mathbf{Z})$ is constructed as follows. First use the policy $\{\operatorname{Tc}(\mathbf{Z}), i(\mathbf{Z})\}_{\mathbf{Z} \in \mathcal{Z}}$ and formula (9) to construct the stochastic discount factor as a function of $\theta^{\prime}$ :

$M\left(\mathbf{Z}, \theta^{\prime}\right)=\beta[1-\delta+i(\mathbf{Z})]^{-\frac{1}{\psi}}\left[\frac{c\left(\phi\left(\mathbf{Z}, \theta^{\prime}\right), \theta^{\prime}, n\left(\mathbf{Z}, \theta^{\prime}\right)\right)}{T c(\mathbf{Z})}\right]^{-\frac{1}{\psi}}\left[\frac{v\left(\phi\left(\mathbf{Z}, \theta^{\prime}\right), \theta^{\prime}, n\left(\mathbf{Z}, \theta^{\prime}\right)\right)}{\left(E\left[v\left(\phi\left(\mathbf{Z}, \theta^{\prime}\right), \theta^{\prime}, n\left(\mathbf{Z}, \theta^{\prime}\right)\right)^{1-\gamma}\right]\right)^{\frac{1}{1-\gamma}}}\right]^{\frac{1}{\psi}-\gamma}$,

and second, the interest rate is constructed from hoursehold's first order condition:

$$
R_{f}(\mathbf{Z})=E\left[M\left(\mathbf{Z}, \theta^{\prime}\right)\right]^{-1}
$$

The equilibrium conditions can be summarized by:

1. Banks' intertemporal optimality condition (32).

2. Optimality with respect to capital reallocation, conditions (33) and (34). 
3. The policy $T \mu(\mathbf{Z})$ satisfies the envelope condition (39):

$$
T \mu(\mathbf{Z})=E\left[M\left(\mathbf{Z}, \theta^{\prime}\right)\left\{\lambda+(1-\lambda) \mu\left(Z, \phi\left(\mathbf{Z}, \theta^{\prime}\right), \theta^{\prime}, n\left(\mathbf{Z}, \theta^{\prime}\right)\right)\right\}\left\{1+\zeta_{H}\left(\mathbf{Z}, \theta^{\prime}\right)+\zeta_{L}\left(\mathbf{Z}, \theta^{\prime}\right)\right\}\right] R_{f}(\mathbf{Z})
$$

4. The limited enforcement constraints, (13), written in normalized terms:

$$
\begin{aligned}
& \left(1-\delta-\theta^{\prime}\right) q\left(\mathbf{Z}^{\prime}\right)-\frac{b_{f}(\mathbf{Z}) R_{f}(\mathbf{Z})}{1-\delta+i(\mathbf{Z})} \geq O\left(\mathbf{Z}^{\prime}\right) \frac{(1-\pi)\left[\phi\left(\mathbf{Z}, \theta^{\prime}\right)-1\right]}{\pi \phi\left(\mathbf{Z}, \theta^{\prime}\right)+1-\pi} \\
& \left(1-\delta-\theta^{\prime}\right) q\left(\mathbf{Z}^{\prime}\right)-\frac{b_{f}(\mathbf{Z}) R_{f}(\mathbf{Z})}{1-\delta+i(\mathbf{Z})} \geq-O\left(\mathbf{Z}^{\prime}\right) \frac{\pi\left[\phi\left(\mathbf{Z}, \theta^{\prime}\right)-1\right]}{\pi \phi\left(\mathbf{Z}, \theta^{\prime}\right)+1-\pi},
\end{aligned}
$$

where we denote $\mathbf{Z}^{\prime}=\left(\phi\left(\mathbf{Z}, \theta^{\prime}\right), \theta^{\prime}, n\left(\mathbf{Z}, \theta^{\prime}\right)\right)$, and the $O\left(\mathbf{Z}^{\prime}\right)$ function is as defined in $(35)$.

5. The resource constraint:

$$
T c(\mathbf{Z})+i(\mathbf{Z})+\frac{1}{2} h\left(i(\mathbf{Z})-i^{*}\right)^{2}=\bar{A} f(\phi)
$$

6. The budget constraint for banks:

$$
T q(\mathbf{Z})[1-\delta+i(\mathbf{Z})]=n+b_{f}(\mathbf{Z})
$$

7. The optimality condition for investment goods producers:

$$
T q(\mathbf{Z})=1+h\left(i(\mathbf{Z})-i^{*}\right)
$$

8. The policy $T v(\mathbf{Z})$ is household continuation utility:

$$
T v(\mathbf{Z})=\left\{(1-\beta) c(\mathbf{Z})^{1-1 / \psi}+\beta[1-\delta+i(\mathbf{Z})]^{1-\frac{1}{\psi}}\left(E\left[v\left(\phi\left(\mathbf{Z}, \theta^{\prime}\right), \theta^{\prime}, n\left(\mathbf{Z}, \theta^{\prime}\right)\right)^{1-\gamma}\right]\right)^{\frac{1-1 \backslash \psi}{1-\gamma}}\right\}^{\frac{1}{1-1 / \psi}}
$$

Note that the above procedure defines a mapping from the space of equilibrium functionals to itself through the $T$ operator. Although the existence and uniqueness of the $T$ operator are difficult to establish in general and are beyond the scope of the current paper, whenever the fixed point does exist, as shown by the proposition below, we can construct 
a Markov equilibrium of our model out of the fixed point of equilibrium functionals. In practice, the $T$ operator gives us a recursive procedure that if convergent, can be used to to compute the equilibrium numerically. Our numerical method is based on the $T$ operator constructed above.

Proposition 3 (Markov Equilibria)

Suppose the $T$ operator has a fixed point in the space of bounded continuous functions, which we denote as

$$
\left\{c^{*}(\mathbf{Z}), v^{*}(\mathbf{Z}), q^{*}(\mathbf{Z}), \mu^{*}(\mathbf{Z})\right\}_{\mathbf{Z} \in \mathcal{Z}}
$$

We can construct a Markov equilibrium as follows:

1. The Markov state variable is $\mathbf{Z}=(\phi, \theta, n)$. The exogenous process $\theta_{t}$ is Markov with state space $\left[\theta_{L}, \theta_{H}\right]$. The law of motion of $n$ is given by (33) and for each realization of $\theta^{\prime}$, the law of motion of $\phi$ is given by $\phi^{\prime}=\phi\left(\mathbf{Z}, \theta^{\prime}\right)$, where $\phi(\mathbf{Z}, \theta)$ is the policy function given the equilibrium functionals in (49).

2. The equilibrium prices can be constructed as follows. Interest rate $R_{f}(\mathbf{Z})$ is given by (41), and the interbank risk-free interest rate is given by (38). The equilibrium price of capital is $q^{*}(\mathbf{Z})$, and for $i=H, L$,

$$
Q_{j}(\mathbf{Z})=M P K_{j}(\phi(\mathbf{Z}))+(1-\delta) q(\mathbf{Z})
$$

3. Given the above price system, given an initial condition of the economy, $\left\{\phi_{0}, \theta_{0}, n_{0}, \bar{K}_{0}\right\}$. Suppose $W_{0}=c\left(\mathbf{Z}_{0}\right) \bar{K}_{0}+q\left(\mathbf{Z}_{0}\right) \bar{K}_{0}\left[1-\delta+i\left(\mathbf{Z}_{0}\right)\right]-\mathbf{n}_{0}$. For $t=0,1,2 \cdots$, let the total capital stock be given by:

$$
\bar{K}^{\prime}=\bar{K}[1-\delta+i(\mathbf{Z})]
$$

and household wealth be given by:

$$
W_{t}=c(\mathbf{Z}) \bar{K}_{t}+q\left(\mathbf{Z}_{t}\right) \bar{K}_{t+1}-n_{t} \bar{K}_{t}
$$

The the optimal policy for households can be constructed as:

$$
\begin{gathered}
C\left(\mathbf{Z}_{t}, W_{t}\right)=c\left(\mathbf{Z}_{t}\right) \bar{K}_{t} \\
B_{f}\left(\mathbf{Z}_{t}, W_{t}\right)=q\left(\mathbf{Z}_{t}\right) \bar{K}_{t+1}^{\prime}-\mathbf{n}_{t} \bar{K}_{t} .
\end{gathered}
$$


4. The optimal policy for banks are given by:

$$
\begin{aligned}
B_{f}\left(\mathbf{Z}_{t}\right) & =b_{f}\left(\mathbf{Z}_{t}\right) \bar{K}_{t} \\
R A_{H}\left(\mathbf{Z}_{t}\right) & =(1-\pi)[\phi(Z)-1] K_{t}, \\
R A_{L}\left(\mathbf{Z}_{t}\right) & =-\pi[\phi(Z)-1] K_{t} .
\end{aligned}
$$

In the above construction, state variables consist of the exogenous shock, $\theta$, and the distribution of capital stock across firms, $\phi$, and normalized bank net worth, $n$. Note that $W$ is a state variable in the household portfolio choice problem, and bank net worth $N$ is a state variable in banks' problem. In general, both $W$ and $N$ should be part of the state variables in the construction of a Markov equilibrium. However, the Walras law implies that $N$ and $W$ must satisfy

$$
N+W=C(\mathbf{Z})+q(\mathbf{Z}) \bar{K}^{\prime}(\mathbf{Z}) .
$$

Therefore, there is only one degree of freedom between $N$ and $W$. We choose bank net worth $N$ to be the state variable in our recursive formulation of the equilibrium.

\section{Quantitative Results}

In this section, we calibrate our model and evaluate its quantitative performance. Our choice of the preference parameters follows the standard long-run risks literature: we choose the risk aversion to be 10, and IES to be 2. Several parameters for the production technology are also standard in the real business cycle literature, for example, capital share and depreciate rate of capital. We choose $\pi=0.1$ so that half of the output are produced by high productivity firms in the first best allocation. We choose the two key parameters that governs the gain from capital reallocation from the estimates of Hsieh and Klenow (2009). We choose the elasticity of substitution among varieties to be $\eta=4$, and $a_{H} / a_{L}=2.08$ to match the interquartile range of the estimated distribution of productivity in Hsieh and Klenow (2009). We choose the productivity parameter $\bar{A}=0.71$ to match the average growth in the U.S. of $1.8 \%$ per year in the post war period. We choose $\beta=0.977$ to match an average risk-free interest rate (the three-month $\mathrm{T}$ Bill rate) of $0.86 \%$. In the quantitative exercise, we use an adjustment cost similar to Gertler and Kiyotaki (2010):

$$
H\left(I_{t}, I_{t-1}\right)=I_{t}+\frac{1}{2} h\left(\frac{I_{t}}{I_{t-1}}-\left(1-\delta+i^{*}\right)\right)^{2}
$$


where $1-\delta+i^{*}$ is the steady-state growth rate of the economy. We set $h=0.65$.

The specification of banks' outside option is important for the quantitative magnitude of the amplification mechanism. We choose the long-run mean of $\theta, \bar{\theta}=0.35$, and $\omega=0.35$. These choices allow us to match the spread between interbank loan and household loan in our model, $R_{I}(Z)-R_{f}(Z)$ with the average TED spread (the spread between LIBOR and U.S. treasury bills rate) of $0.64 \%$ during our sample period of 1986-2011. In addition, it implies that in steady state, $90 \%$ of total investment are financed by capital reallocation.

The amount of capital reallocation in our calibration is quite large. Empirical evidence suggests that for publicly traded firms, about $25 \%$ of total investment are financed from external funds, for example Eisfeldt and Rampini (2006). Using UK data for privately held firms, Shourideh and Zetlin-Jones (2012) find roughly 95\% of investment are externally financed. We choose to match a moment that is closer to the evidence for private firms. Note that a smaller amount of capital reallocation implies that firms are more constrained in the steady-state. This implies that total output is more sensitive to capital misallocation. From this point of view, our calibration may understate the effect of capital reallocation. ${ }^{13}$

We choose the autocorrelation of $\theta$ to be 0.95 , so that the equilibrium consumption dynamics are consistent with that in the long-run risks literature. We do not have much guidance in choosing the volatility of innovations in $\theta_{t}$, we set it to be $8 \%$ per year, this produces a volatility of total output of $2.5 \%$ per year, comparable to the volatility of total output in the data. Even if the volatility of $\theta$ is not directly observable, the volatility of the inter-bank risk-free interest rate can be used to discipline this moment. Large volatility in innovations in $\theta$ will produce excessive volatility in inter-bank lending rates. The volatility of interbank interest rate in our model is $2.08 \%$ per year, matching closely the volatility of annualized three-month LIBOR in the data, $2.16 \%$ per year.

We display the moments of macroeconomic quantities generated by our model in Table 2. These moments are comparable to standard real business cycle models in that our model produces a low volatility in consumption and a much higher volatility in investment. However, the correlation between consumption and investment is considerable lower than their data counterpart and than that in standard RBC models. Note our model does not have productivity shocks, but behave like a model with TFP shocks in terms of macroeconomic fluctuations. Most of the volatility in output are generated from misallocation. The

\footnotetext{
${ }^{13}$ At the same time, because financial friction is the only friction that affects capital reallocation, our model would produce too high an interest rate on the interbank market if calibrated to match lower levels of capital reallocation. This is why we do not entertain this possibility here.
} 
volatility of of the efficiency measure, $f(\phi)$ is $2.05 \%$ per year, accounting for almost all of the variations in total output, the rest of the volatility originating from variations in capital accumulation. The cross-sectional variance of measured marginal product of capital in our model is quite volatile (2.8\% per year), and is highly countercyclical: its correlation with measure TFP is $-62 \%$ at the annual level.

Financial shocks in our model generate a significant amount of fluctuations in macroeconomic quantities despite the small amount of volatility in shocks to $\theta$. Two features are responsible for the significant impact of agency frictions on aggregate output in our model. First, the total amount of capital are predetermined as in neoclassical models; however, capital reallocation happens immediately after the realization of productivity shocks and affect current period output directly. This aspect of our model captures the idea that transfer of ownership of capital happens at a higher frequency than the formation of capital. Quantitatively, it allows shocks to translate into misallocation immediately, generating significant impact on total output. Kocherlakota (2000) points out that credit market frictions are unlikely to have a large impact on real output in models where these frictions restrict intertemporal capital accumulation. The basic reason is that investment account for about $10 \%$ of capital and capital income account for about $1 / 3$ of total income. Roughly speaking, a one dollar reduction in investment will translate into a decrease in next period output by about three cents, a fairly small number. Similar to us, in a model where financial constraints affect current period output directly, Jermann and Quadrini (2012) also find credit market frictions to have a quantitatively large impact on real quantities. ${ }^{14}$

The second reason for the significant impact of financial frictions is the equilibrium amplification mechanism. To understand this point, note that whenever $O\left(\mathbf{Z}^{\prime}\right)>0$, the limited commitment constraint on low islands does not bind, and $Q\left(\mathbf{Z}^{\prime}\right)=Q_{L}\left(\mathbf{Z}^{\prime}\right) \cdot{ }^{15}$ In this case, the term $O\left(\mathbf{Z}^{\prime}\right)$ can be written as: $(1-\omega) M P K_{L}\left(\phi^{\prime}\right)+[\theta-\omega(1-\delta)] q\left(\mathbf{Z}^{\prime}\right)$ and constraint (43) becomes

$$
\left(1-\delta-\theta^{\prime}\right) q\left(\mathbf{Z}^{\prime}\right)-\frac{b_{f}(\mathbf{Z}) R_{f}(\mathbf{Z})}{1-\delta+i(\mathbf{Z})} \geq\left[\begin{array}{c}
(1-\omega) M P K_{L}\left(\phi^{\prime}\right)+ \\
{[\theta-\omega(1-\delta)] q\left(\mathbf{Z}^{\prime}\right)}
\end{array}\right] \frac{(1-\pi)\left[\phi\left(\mathbf{Z}, \theta^{\prime}\right)-1\right]}{\pi \phi\left(\mathbf{Z}, \theta^{\prime}\right)+1-\pi} .
$$

The left hand side of the above constraint is the net benefit of continuation, and the

\footnotetext{
${ }^{14}$ In a similar model where limited enforcement affect capital reallocation in the next period, but not current period, we found that capital market frictions affect mainly intertemporal investment, and their impact on misallocation is typically negligible.

${ }^{15}$ See Appendix D
} 
right hand side is the net benefit of default. An additional unit of capital increases the net benefit of continuation by $\left(1-\delta-\theta^{\prime}\right) q\left(\mathbf{Z}^{\prime}\right)$, because it increases bank net worth by $(1-\delta) q\left(\mathbf{Z}^{\prime}\right)$ and raises the value of default by $\theta^{\prime} q\left(\mathbf{Z}^{\prime}\right)$. The term $\frac{b_{f}(\mathbf{Z}) R_{f}(\mathbf{Z})}{1-\delta+i(\mathbf{Z})}$ is bankers' debt liability normalized by the size of capital. The term $\frac{(1-\pi)\left[\phi\left(\mathbf{Z}, \theta^{\prime}\right)-1\right]}{\pi \phi\left(\mathbf{Z}, \theta^{\prime}\right)+1-\pi}$ is the amount of capital reallocated to high productivity islands (normalized by the size of capital stock), and $O\left(\mathbf{Z}^{\prime}\right)=(1-\omega) M P K_{L}\left(\phi^{\prime}\right)+[\theta-\omega(1-\delta)] q\left(\mathbf{Z}^{\prime}\right)$ is the marginal benefit of default per unit of capital purchased on the reallocation market. The parameter $\omega>0$ captures the idea that banks are better than households in enforcing lending contracts.

An increase in $\theta^{\prime}$ tightens banks' borrowing constraint for two reasons. The first is a direct effect because it increases bankers' outside option. This is captured by the fact that the left hand side of (53) is decreasing and the right hand side is increasing in $\theta^{\prime}$, keep all else constant. The second effect is an equilibrium mechanism. High values of $\theta^{\prime}$ implies that banks are more constrained and are under pressure to sell their assets. In addition, the persistence of $\theta^{\prime}$ implies future production will be less efficient and the marginal product of capital is likely to be low. Both forces tend to lower the value of capital $q\left(\mathbf{Z}^{\prime}\right)$. This further decreases the value of continuation on the left hand side of (53). ${ }^{16}$ Furthermore, both effects are amplified by leverage: a small percentage change in in the term $\left(1-\delta-\theta^{\prime}\right) q\left(\mathbf{Z}^{\prime}\right)$ may result in a large percentage in the left hand side of (53) if bank debt is large. We choose a conservative calibration where the steady-state bank leverage in our model is about 1.67. The amplification effect in our model will be stronger if we target a bank leverage of four as in Gertler and Kiyotaki (2010). ${ }^{17}$ Whenever constraint (53) is binding, variations in $\theta^{\prime}$ and $q\left(\mathbf{Z}^{\prime}\right)$ must the absorbed by interbank borrowing, $\frac{(1-\pi)\left[\phi\left(\mathbf{Z}, \theta^{\prime}\right)-1\right]}{\pi \phi\left(\mathbf{Z}, \theta^{\prime}\right)+1-\pi}$, resulting in large variations in capital reallocation and aggregate output.

To better under understand the amplification mechanism in our model, we display calibrated moments for two other models in Table 2. We consider a model with TFP shocks only (column "TFP shocks") and shocks to capital depreciation rates only (column "Dep Shocks"). As in many papers that emphasize the amplification mechanism, credit market frictions amplify the impact of productivity shocks on the real economy in the model with

\footnotetext{
${ }^{16}$ Note that decreases in $q\left(\mathbf{Z}^{\prime}\right)$ may also lower banker's outside options, which is the right-hand side of (53). However, when $\omega$ is large, the coefficient $\theta-\omega(1-\delta)$ is small or even negative. Intuitively, upon default, bankers take all of the current period profit, $M P K_{L}\left(\phi^{\prime}\right)$, and a fraction $\theta^{\prime}$ of the capital stock. If frictions on interbanking borrowing is relatively small most of the capital stock borrowed from the interbank market must be returned to the lending bank. This makes default less attractive when market valuation $q\left(\mathbf{Z}^{\prime}\right)$ is high.

${ }^{17}$ However, a leverage ratio of four implies an unreasonably high inter-bank interest rate in our model. We therefore chose not to target the same moment in our calibration.
} 
TFP shocks only. In the model with capital depreciation shocks, we follow Gertler and Kiyotaki (2010) and inject exogenous shocks to the capital depreciation rate, $\delta_{t}$. The volatility of exogenous shocks and the adjustment cost parameters in both calibrations are chosen to match the volatility of consumption and investment with those in the benchmark model with $\theta$ shocks. All other parameters are the same as those in the benchmark calibration.

We note that the volatility of the efficiency of capital reallocation, $f(\phi)$ in both calibrations is an order of magnitude smaller than the model with financial shocks (shocks to $\theta$ ). The reason for this is that these models generate very small volatility in Tobin's q. This highlights another difficulty for credit market frictions to generate a large impact on the real economy in general equilibrium models with financial intermediaries. In most models with financial intermediaries, credit market frictions affect the real economy because changes in intermediary net worth affect their borrowing capacity. However, it is a well known difficulty that standard general equilibrium production economies produce very little variation in the price of capital (unless one is willing to entertain the possibility of large fluctuations in discount rates or extraordinarily low levels of investment volatility). As a result, although many endowment based models with financial intermediary are able to generate large financial crisis, it is not clear whether one can generalize those results and conclude a large impact on the real economy. The amplification effect in the model with TFP shocks are fairly small for exactly this reason. In the model with depreciation shocks, the amplification effect could be potentially large if one is willing to specify a large volatility of capital depreciation. However, this will have to be associated with large variations in the capital stock and counterfactually high levels of volatility in total output that comes from changes in capital stock.

We now turn to the asset pricing implications of the model, which we report in Table 3. Our model produces a low and smooth risk-free interest rate as in standard long-run risks models due to the high intertemporal elasticity of substitution. Our model improves significantly upon standard long-run risks production models in several dimensions. First, our model generates a significant risk premium of the market return, $3.63 \%$ per year without accounting for financial leverage. Part of the equity premium is due to liquidity premium, in the sense that when banks are constrained they cannot purchase more capital despite the high expected return. The liquidity premium account for roughly $0.9 \%$ of the equity premium in our calibration. The rest of the equity premium is compensation for risks. Thanks to the persistence of the finance shocks and the linear technology, our model endogenously generates long-run risks as in Ai (2010) and Kung and Schmid (2013), and therefore features a very volatile pricing kernel as in standard long-run risks models. Second, our mode generates 
significant volatility on the return on equity. The volatility of the unlevered equity return is $3.59 \%$, significantly higher than standard production economies. In addition, the level and volatility of the risk-free interbank lending rate in our model is quite in line with the data.

Note also that our model endogenously generates persistent and countercyclical volatility in aggregate consumption. In our model, both idiosyncratic and aggregate volatility are counter-cyclical. In periods with tightened financial constraints, capital reallocation is limited. This implies that most of the idiosyncratic productivity shocks must be absorbed by prices. As a result, the cross-sectional dispersion of price of capital and return on equity widens. In our model, the correlation between the cross-sectional variance of return on capital and GDP growth is $-63 \%$. At the same time, our model features counter-cyclical volatility of aggregate consumption, as in standard endowment based long-run risk models. The correlation of consumption volatility and GDP growth in our simulated model is about $-13 \%$ at the annual level, and increases to $-47 \%$ at a five-year horizon. Variations of aggregate volatility is determined by the joint dynamics of net worth and $\theta$. Within a period for a fixed level of debt, small values $\theta$ improves capital reallocation. As $\theta$ becomes smaller, output becomes less sensitive to capital reallocation. In fact, when constraint (53) stops binding, output is independent of $\theta$. Therefore, growth and volatility is negatively correlated within a period. Over longer horizons, continued negative shocks depletes bank net worth and increases leverage. This makes the economy more vulnerable to shocks on the financial market, and increases the volatility level at lower frequencies.

\section{Conclusion}

We presented a general equilibrium model with financial intermediary and capital reallocation. Our model emphasize the role of financial intermediary in reallocating capital across firms with heterogenous productivity. We show that shocks to financial frictions alone may account for a large fraction in the fluctuations of measured TFP and aggregate output. Our calibrated model is consistent with the salient features of business cycle variations in macroeconomic quantities and asset prices. It improves substantially over stand RBC models in terms of asset pricing implications.

An important next step is to infer or impute shocks to financial frictions from the data

and investigate whether our model can account for the realized variations in macroeconomic quantities and asset prices once these shocks are fed into the model. One possible way is to infer financial frictions from the dispersion in the marginal product of capital in the data. 
The close link between the dispersion measure and TFP in Figure 1 suggests that our model hold promises. A stronger discipline may be imposed on the model if we can infer shocks to $\theta$ directly from banks' balance sheet variables. We leave this for future research. 


\section{Appendix}

\section{A Misallocation and Aggregation on the Product Market}

\section{Aggregation}

We first derive an aggregation result that is similar to Hsieh and Klenow (2009) and Hopenhayn and Neumeyer (2008). In fact, the product market of our model is a special case of Hsieh and Klenow (2009) and Hopenhayn and Neumeyer (2008) without labor market distortions.

Consider the maximization problem in (3), first order conditions with respect to $k(j)$ and $l(j)$ imply:

$$
\begin{aligned}
(1-\alpha)\left(1-\frac{1}{\eta}\right) p_{j} y_{j} & =M P L \cdot l_{j} \\
\alpha\left(1-\frac{1}{\eta}\right) p_{j} y_{j} & =M P K_{j} \cdot k_{j}
\end{aligned}
$$

Together, the above imply:

$$
\frac{k_{j}}{l_{j}}=\frac{M P L}{M P K_{j}} \frac{\alpha}{1-\alpha}
$$

To save notation, we denote $A_{j}=A a(j)$ in this section. Note also, total output of firm j can be written as:

$$
\begin{aligned}
y_{j} & =A_{j} k_{j}^{\alpha} l_{j}^{1-\alpha}=A_{j}\left[\frac{k_{j}}{l_{j}}\right]^{\alpha} l_{j} \\
& =A_{j}\left[\frac{l_{j}}{k_{j}}\right]^{1-\alpha} k_{j} .
\end{aligned}
$$

Using (56) and (57), we can write $l_{j}$ as a function of $y_{j}$ :

$$
l_{j}=\frac{y_{j}}{A_{j}}\left[\frac{\alpha M P L}{(1-\alpha) M P K_{j}}\right]^{-\alpha} .
$$

Similarly, (56) and (58) together implies

$$
k_{j}=\frac{y_{j}}{A_{j}}\left[\frac{\alpha M P L}{(1-\alpha) M P K_{j}}\right]^{1-\alpha} .
$$

Using the demand function $p_{j}=\left[\frac{y_{j}}{Y}\right]^{-\frac{1}{\eta}}$, we can replace $y_{j}$ in the above equations by $p_{j}^{-\eta} Y$, 
and integrate across all $j$, we have:

$$
\begin{aligned}
\bar{K} & =\int \frac{p_{j}^{-\eta}}{A_{j}}\left[\frac{1}{M P K_{j}}\right]^{1-\alpha} d j\left[\frac{\alpha M P L}{1-\alpha}\right]^{1-\alpha} Y \\
\bar{L} & =\int \frac{p_{j}^{-\eta}}{A_{j}}\left[\frac{1}{M P K_{j}}\right]^{-\alpha} d j\left[\frac{\alpha M P L}{1-\alpha}\right]^{-\alpha} Y
\end{aligned}
$$

where $\bar{K}$ and $\bar{L}$ stands for the total capital and total labor employed for production, respectively. Together, (61) and (62) imply

$$
Y=\frac{\bar{K}^{\alpha} \bar{L}^{1-\alpha}}{\left[\int \frac{p_{j}^{-\eta}}{A_{j}}\left[\frac{1}{M P K_{j}}\right]^{1-\alpha} d j\right]^{\alpha}\left[\int \frac{p_{j}^{-\eta}}{A_{j}}\left[\frac{1}{M P K_{j}}\right]^{-\alpha} d j\right]^{1-\alpha}} .
$$

We can express $p_{j}$ in (63) by functions of productivity and prices. Note that (54) and (55) imply

$$
M P K_{j} \cdot k_{j}+M P L \cdot l_{j}=\left(1-\frac{1}{\eta}\right) p_{j} y_{j}
$$

Using (59) and (60), we have:

$$
M P K_{j} \cdot k_{j}+M P L \cdot l_{j}=\frac{y_{j}}{A_{j}}\left[\frac{M P L}{(1-\alpha)}\right]^{1-\alpha}\left[\frac{M P K_{j}}{\alpha}\right]^{\alpha} .
$$

Combining (64) and (65), we have:

$$
p_{j}=\frac{\eta}{\eta-1} \frac{1}{A_{j}}\left[\frac{M P L}{(1-\alpha)}\right]^{1-\alpha}\left[\frac{M P K_{j}}{\alpha}\right]^{\alpha} \text {. }
$$

Note that the normalization of price we choose in $(2)$ implies $\int p_{j} d j=1$. Integrating (66) over $j$, we have:

$$
\frac{\eta}{\eta-1}\left[\frac{M P L}{(1-\alpha)}\right]^{1-\alpha}=\left\{\int \frac{1}{A_{j}}\left[\frac{M P K_{j}}{\alpha}\right]^{\alpha} d j\right\}^{-1} .
$$

Together, (66) and (67) imply

$$
p_{j}=\frac{\frac{1}{A_{j}}\left[\frac{M P K_{j}}{\alpha}\right]^{\alpha}}{\int \frac{1}{A_{j}}\left[\frac{M P K_{j}}{\alpha}\right]^{\alpha} d j}
$$

Replacing $p_{j}$ in equation (63) with (68), and using $A_{j}=A^{1-\alpha} a(j)$, we can write $Y=$ 
$T F P \bar{K}^{\alpha} \bar{L}^{1-\alpha}$, where

$$
T F P=A \frac{\left\{\int\left(\frac{a_{j}}{M P K_{j}^{\alpha}}\right)^{\eta-1} d i\right\}^{\frac{\eta}{\eta-1}+\alpha-1}}{\left\{\int\left(\frac{a_{j}}{M P K_{j}^{\alpha}}\right)^{\eta-1} \frac{1}{M P K_{j}} d i\right\}^{\alpha}} .
$$

Under the assumption (4), it is straightforward to show that TFP $=A$ is $M P K_{j}=M P K$ for all $j$. We define

$$
E F=\frac{\left\{\int\left(\frac{a_{j}}{M P K_{j}^{\alpha}}\right)^{\eta-1} d i\right\}^{\frac{\eta}{\eta-1}+\alpha-1}}{\left\{\int\left(\frac{a_{j}}{M P K_{j}^{\alpha}}\right)^{\eta-1} \frac{1}{M P K_{j}} d i\right\}^{\alpha}}
$$

to be the efficiency measure of capital reallocation. Under the assumption $\ln \alpha_{j}$ and $\ln M P K_{j}$ are jointly normally distributed, we can show that

$$
\ln E F=-\frac{1}{2}[\alpha(\eta-1)+1] \alpha \sigma^{2},
$$

where $\sigma^{2}$ is the cross-sectional variance of marginal product of capital. Note also, (71) is approximately true for arbitrary distributions as long as the deviation of $\ln \alpha_{j}$ and $\ln M P K_{j}$ from there mean is small. Therefore, (71) can be viewed as a first order Taylor approximation that maps the cross-sectional variance of marginal product of capital into TFP losses due to misallocation.

\section{Proof of Proposition 1}

In the special case where $a_{j}$ takes on only two values, $a_{H}$ and $a_{L}$ as in (5), we define $\phi=\frac{K_{H}}{K_{L}}$ to be the ratio of capital employed on islands with high productivity shock with respect to that employed on islands with low productivity shock, as in (28). Note that

$$
M P K_{j}=\alpha A a_{j}\left(\frac{l_{j}}{k_{j}}\right)^{1-\alpha} ; \quad M P L=(1-a) A a_{j}\left(\frac{k_{j}}{l_{j}}\right)^{\alpha} .
$$

Note that because labor market is perfectly mobile, $M P L$ must equalize across all islands. Using the labor market clearing condition, (19) and assumption (6), we can prove conditions (30) and (31). Using there conditions to replace $M P K_{j}$ in (70), the efficiency measure (70) can be written as (29). This completes the proof of Proposition 1. 


\section{B Data Construction}

\section{B.1 Misallocation and TFP}

In Figure 1, we plot the measure of capital misallocation and total factor productivity. We measure the cross-sectional dispersion of TFPR following Hsieh and Klenow (2009). In the context of our model, equation (55) implies

$$
M P K_{j}=\alpha\left(1-\frac{1}{\eta}\right) \frac{p_{j} y_{j}}{k_{j}} .
$$

Following Chen and Song (2013), we measure $M P K_{j}$ by the ratio of Operating Income before Depreciation (OIBDP) to one-year-lag net Plant, Property and Equipment (PPENT). As in Hsieh and Klenow (2009), we focus on the manufacturing sector and compute the crosssectional dispersion measure within narrowly defined industries (as classified by the 4-digit standard industry classification code). Specifically, for firm $j$ in industry $i$, we compute

$$
\frac{M P K_{i, j}}{M P K_{i}}=\frac{\alpha\left(1-\frac{1}{\eta}\right) \frac{p_{i, j} y_{i, j}}{k_{i, j}}}{\alpha\left(1-\frac{1}{\eta}\right) \frac{p_{j} y_{j}}{k_{j}}}=\frac{\frac{p_{i, j} y_{i, j}}{k_{i, j}}}{\frac{p_{j} y_{j}}{k_{j}}}
$$

where $\frac{p_{j} y_{j}}{k_{j}}$ is measured at the industry level. We than compute the variance of $\frac{M P K_{i, j}}{M P K_{i}}$ for each year. This is our empirical measure of $\sigma^{2}$ in equation (71). We use the first order approximation in (71) to construct the time series of the misallocation measure, which is the solid line in Figure 1. The measure of total factor productivity is directly taken from the published TFP series on the Federal Reserve Bank of St Louis website. Both series are HP filtered.

\section{B.2 Total Volume of Bank Loans}

We measure the total volume of bank loans of non-financial corporate sector through the aggregate balance sheet of nonfinancial corporate business (Table B.102) as reported in the U.S. Flow of Funds Table. In particular, the bank loan is calculated as the difference between total credit market liability (Line 23) and corporate bond (Line 26). Under this construction, bank loans consist of the following credit market liability items: commercial paper (Line 24), municipal securities (Line 25), depository institution loans (Line 27), other loans and advances (Line 28) and mortages (Line 29). 


\section{The Two-Period Model}

Consider the bank's optimization problem. Let $\zeta_{H}$ and $\zeta_{L}$ be the Lagrangian multipliers of constraints (26) and (27). The first order conditions of the optimization problem imply:

$$
\begin{gathered}
E\left[M\left(1+\zeta_{H}+\zeta_{L}\right) Q\right]=E\left[M\left(1+\zeta_{H}+\zeta_{L}\right)\right] R_{f} . \\
\zeta_{H}=\frac{\pi\left(Q_{H}-Q\right)}{Q-(1-\theta) Q_{H}} ; \quad \zeta_{L}=\frac{(1-\pi)\left(Q_{L}-Q\right)}{Q-(1-\theta) Q_{L}} .
\end{gathered}
$$

Dividing both sides of banks' budget constraint by $K_{0}$, we have:

$$
1-\delta+i=b_{f}+n
$$

where we denote $n=\frac{N_{0}}{K_{0}}$ and $b_{f}=\frac{B_{f}}{K_{0}}$. Also, using the market clearing condition (17), $R A_{H}=(1-\pi)(\phi-1) K_{1}$ and $R A_{L}=-\pi(\phi-1) K_{1}$. Dividing both sides by $K_{1}$, we can rewrite (26) and (27) as:

$$
\begin{aligned}
& (1-\theta) Q_{H}-\frac{R_{f} b_{f}}{1-\delta+i} \geq\left[Q-(1-\theta) Q_{H}\right] \frac{(1-\pi)(\phi-1)}{\pi \phi+1-\pi} \\
& (1-\theta) Q_{L}-\frac{R_{f} b_{f}}{1-\delta+i} \geq-\left[Q-(1-\theta) Q_{L}\right] \frac{\pi(\phi-1)}{\pi \phi+1-\pi}
\end{aligned}
$$

In addition, $\zeta_{H}>0$ implies that (75) must hold with equality, and $\zeta_{L}>0$ implies that (76) must hold with equality. Because of log preference, the stochastic discount factor $M$ can be written as:

$$
M=\frac{\beta\left(A_{0}-i\right)}{A f(\phi)(1-\delta+i)} .
$$

Finally, the household first order condition implies

$$
R_{f}=\frac{1}{E[M]}=\frac{A(1-\delta+i)}{\beta\left(A_{0}-i\right) E\left[\frac{1}{f(\phi)}\right]}
$$

Together, equations (72)-(78) give us eight equations to solve for the eight equilibrium quantities, $\zeta_{H}, \zeta_{L}, Q, \phi, R_{f}, M, b_{f}$, and $i$ as a function of $n .{ }^{18}$ Conversely, because the optimization problem of households, banks and firms are all standard convex programming problems, any solution to the system of equations (72)-(78) can be used to construct an

\footnotetext{
${ }^{18}$ Strictly speaking, in the case where $\theta$ is uniformly distributed, (73), (75), and (76) are four equations for each possible realizations of $\theta$. Also, the equilibrium quantities, $\zeta_{H}, \zeta_{L}, Q, \phi$ are all functions of $\theta$.
} 
equilibrium in the two-period model.

To prove Proposition 2, note that if $n \geq n^{*}$, then the first best allocation,

$$
\begin{aligned}
i^{*} & =\frac{\left(1-\frac{1}{\eta}\right) \beta A_{0}-(1-\delta)}{1+\left(1-\frac{1}{\eta}\right) \beta} ; \quad \phi(\theta)=\hat{\phi} ; \\
Q_{H}(\theta) & =Q_{L}(\theta)=Q(\theta)=\left(1-\frac{1}{\eta}\right) A
\end{aligned}
$$

constitute a solution to the equilibrium system with $\zeta_{h}=\zeta_{L}=0$. One can verify that in this case both inequalities (75) and (76) are satisfied.

To construct equilibrium quantities for $n<n^{*}$, we first prove the following claim.

Claim $1 Q(\theta) \leq Q_{j}(\theta)$ for $j=H, L$. In addition, $Q(\theta)<Q_{H}(\theta)$ implies that constraint (75) must bind and $Q(\theta)<Q_{H}(\theta)$ implies that constraint (76) must bind.

Proof. If $Q(\theta)>Q_{H}(\theta)$, then the bank can choose $R A(\theta)$ to be arbitrarily large to increase profit unboundedly. This cannot be consistent with any equilibrium. If $Q(\theta)<Q_{j}(\theta)$, then equation (73) implies that $\zeta_{j}(\theta)$ must be positive, and therefore the corresponding constraint must be binding.

To prove Proposition 2, note that in the case where $\theta_{H}=\theta_{L}$, all equilibrium quantities and prices are deterministic and the equilibrium conditions can be reduced to:

$$
\begin{aligned}
\frac{\left(1-\frac{1}{\eta}\right) \beta\left(A_{0}-i\right)}{1-\delta+i} \frac{\pi \phi+1-\pi}{\pi \hat{\phi}^{1-\xi} \phi^{\xi}+1-\pi} \chi & =1, \\
\left(1-\frac{1}{\eta}\right) \frac{(1-\theta) \hat{\phi}^{1-\xi} \phi^{\xi}-\chi(1-\pi)(\phi-1)}{\pi \hat{\phi}^{1-\xi} \phi^{\xi}+1-\pi} & =\frac{1-\delta+i-n}{\beta\left(A_{0}-i\right)} \\
\left(1-\frac{1}{\eta}\right) \frac{(1-\theta)+\chi \pi(\phi-1)}{\pi \hat{\phi}^{1-\xi} \phi^{\xi}+1-\pi} & =\frac{1-\delta+i-n}{\beta\left(A_{0}-i\right)} .
\end{aligned}
$$

Let $\hat{n}$ be the solution to the above system with $\chi=1$ (therefore, we have three unknowns, $\phi, i$, and $\hat{n})$. One can show that if $n \in\left(\hat{n}, n^{*}\right)$, equation (79) and (80) have a solution for $\phi$ and $i$ under the condition $\chi=1$. This solution can be used to construct the equilibrium price:

$$
Q_{H}=M P K_{H}(\phi) ; Q=Q_{L}=M P K_{L}(\phi),
$$

where $M P K_{H}(\phi)$ and $M P K_{L}(\phi)$ are given by (30) and (31). It is straight forward to verify 
in this case $\zeta_{H}>0$ and $\zeta_{L}=0$ and all equilibrium conditions are satisfied. In the case $n \in(0, \hat{n})$, equations (79)-(81) have a solution in terms of $\phi, i$ and $\chi$ with $\chi<1$. The equilibrium prices can be constructed as:

$$
Q_{H}=M P K_{H}(\phi) ; Q_{L}=M P K_{L}(\phi) ; Q=\chi Q_{L} .
$$

One can verify that in this case $\zeta_{H}, \zeta_{L}>0$ and both constraints (75) and (76) are binding.

\section{Computation Details}

We provide details of the numerical method that we use to compute the Markov equilibrium in the paper. We first need to make some simplifications of the equilibrium conditions.

Claim 2 Assume $O\left(\mathbf{Z}^{\prime}\right)>0$ for all $\mathbf{Z}^{\prime}$, where the function $O\left(\mathbf{Z}^{\prime}\right)$ is defined in (35), then constraint (44) does not bind and $Q\left(\mathbf{Z}^{\prime}\right)=Q_{L}(\mathbf{Z})$ for all $\mathbf{Z}^{\prime}$.

Proof. Note the if $O\left(\mathbf{Z}^{\prime}\right)>0$ then inequality (43) implies (44). In this case, $\zeta_{L}\left(Z^{\prime}\right)=0$ and $Q\left(\mathbf{Z}^{\prime}\right)=Q_{L}(\mathbf{Z})$ for all $\mathbf{Z}^{\prime}$ by equation (34).

The above claim reduces the number of policy functions in the equilibrium construct. We use the following procedure to numerically solve the model.

1. Start from an initial guess of the equilibrium functional, $\left\{c^{n}(\mathbf{Z}), v^{n}(\mathbf{Z}), q^{n}(\mathbf{Z}), \mu^{n}(\mathbf{Z})\right\}$ with $n=0$.

2. Start from an initial guess of the policy functions associated with the equilibrium functional with $m=0$ :

$$
\left\{T c^{n, m}(\mathbf{Z}), T v^{n, m}(\mathbf{Z}), T q^{n, m}(\mathbf{Z}), T \mu^{n, m}(\mathbf{Z}), i^{n, m}(\mathbf{Z}), b_{f}^{n, m}(\mathbf{Z}),\left[\zeta_{H}^{n, m}(\mathbf{Z}, \boldsymbol{\theta}), \zeta_{L}^{n, m}(\mathbf{Z}, \theta), \phi^{n, m}(\mathbf{Z}, \theta)\right.\right.
$$

3. Use the policy function to construct the law of motion of the state variables according to (40). Using conditions 1-8 to construct policy functions given the law of motion of state variables. Update the policy functions and set $m=m+1$.

4. Iterate on step 2-3 until the policy functions converge. That is, the policy functions that are used to construct the law of motion of the state variables also solves the equilibrium conditions. The new policy functions are denoted as

$$
\left\{T c^{n}(\mathbf{Z}), T v^{n}(\mathbf{Z}), T q^{n}(\mathbf{Z}), T \mu^{n}(\mathbf{Z}), i^{n}(\mathbf{Z}), b_{f}^{n}(\mathbf{Z}),\left[\zeta_{H}^{n}(\mathbf{Z}, \boldsymbol{\theta}), \zeta_{L}^{n}(\mathbf{Z}, \theta), \phi^{n}(\mathbf{Z}, \theta), Q^{n}(\mathbf{Z}, \theta)\right]_{\theta \in\left[\theta_{L}, \theta_{H}\right.}\right.
$$


5. Set

$$
\begin{aligned}
c^{n+1}(\mathbf{Z}) & =T c^{n}(\mathbf{Z}) \\
v^{n+1}(\mathbf{Z}) & =T v^{n}(\mathbf{Z}) \\
q^{n+1}(\mathbf{Z}) & =T q^{n}(\mathbf{Z}) \\
\mu^{n+1}(\mathbf{Z}) & =T \mu^{n}(\mathbf{Z})
\end{aligned}
$$

and update the equilibrium functional. Iterate step 1-5 until convergence.

The above procedure, if convergent, allows us to construct the Markov equilibrium as the fixed point of the operator described in Section V. 
Figure 1: Log TFP and Capital Misallocation Measured in Log TFP Units

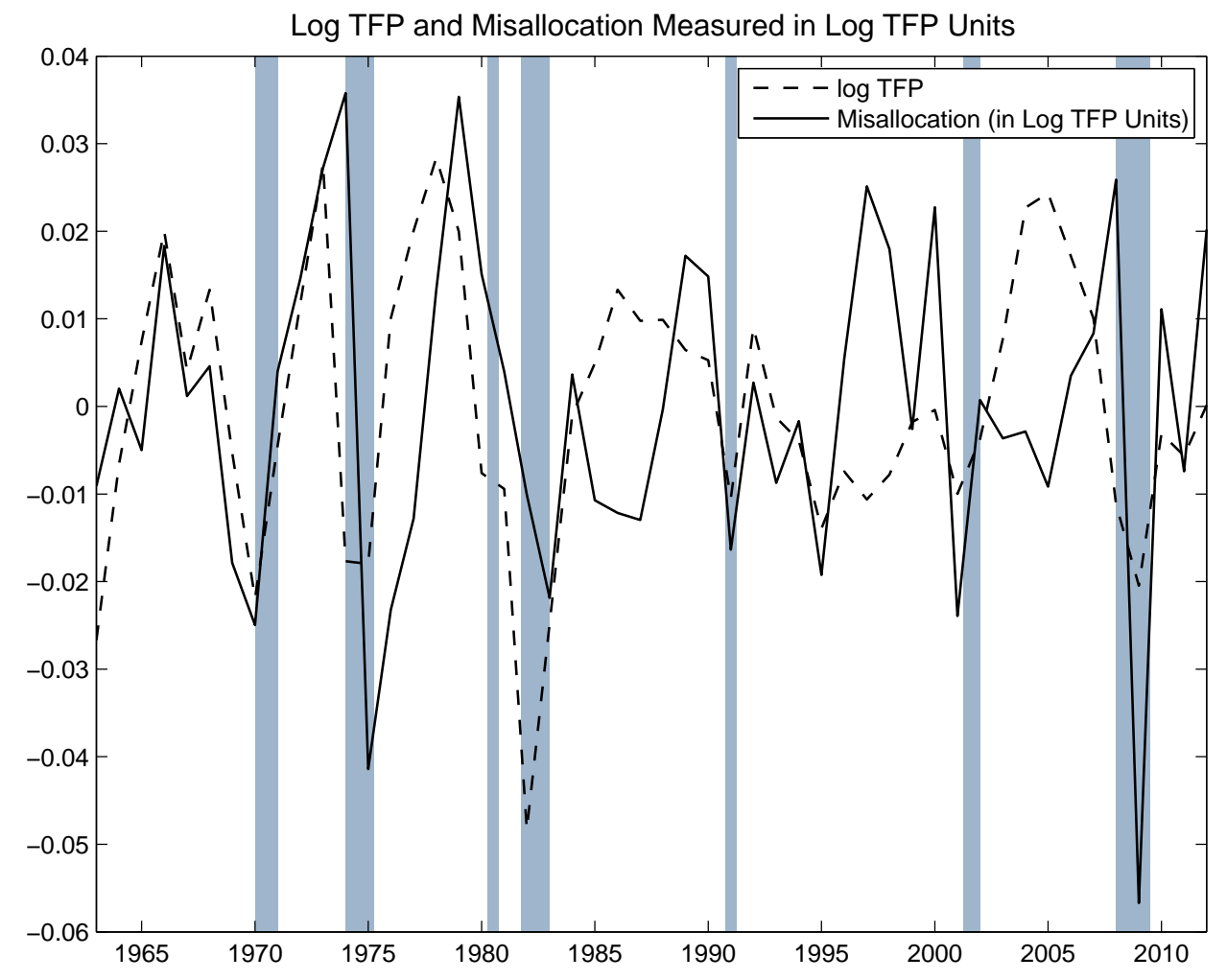

Figure 1 plots the time series of total factor productivity (dashed line) in the U.S. and the measure of capital misallocation (solid line) in the period 1963-2012. The construction of the misallocation measure follows Hsieh and Klenow (2009). We provide the details of the construction in Appendix B. We use the first order Taylor expansion in equation (71) to translate the misallocation measure into log TFP units. Both series are HP filtered. 
Figure 2: Capital Misallocation and Capital Utilization

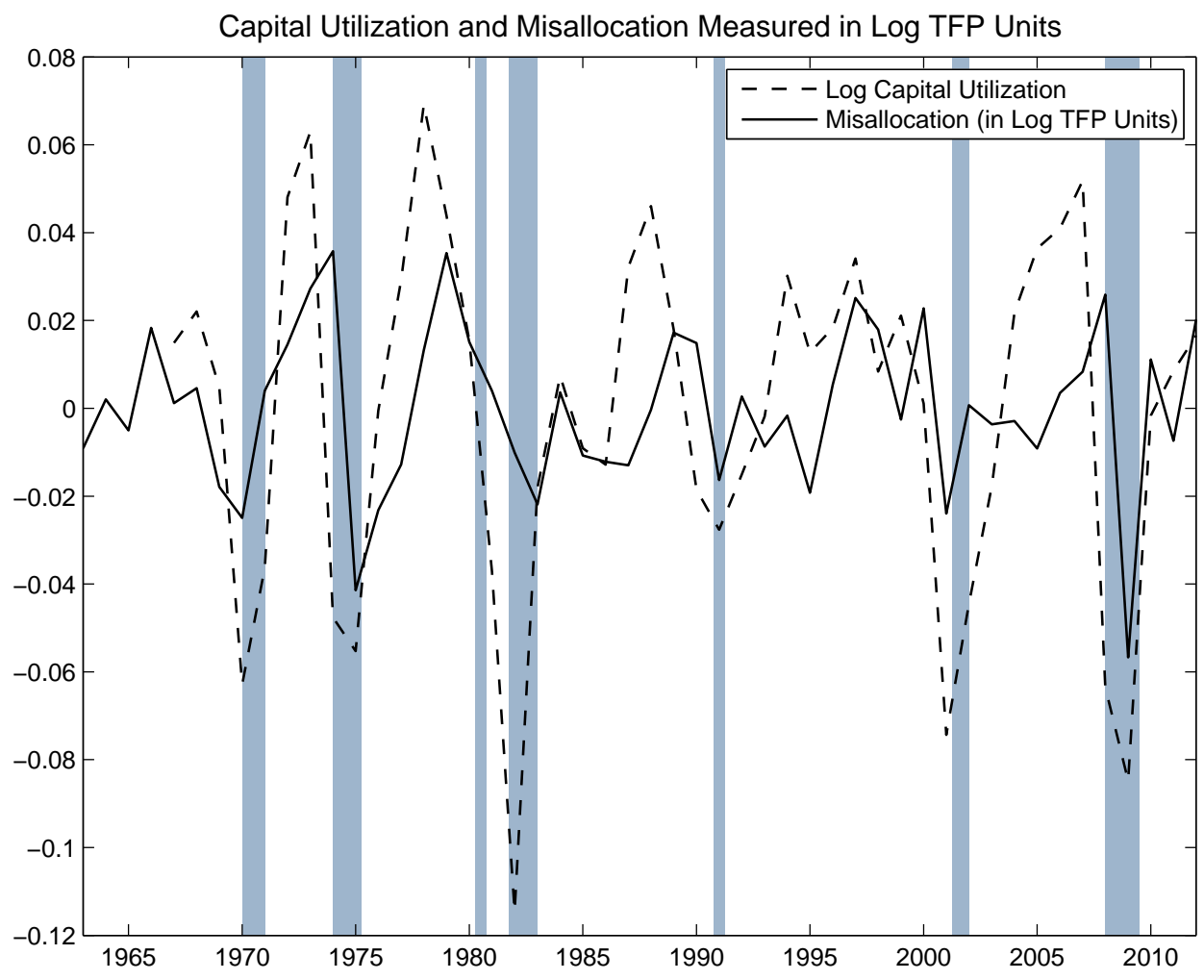

Figure 2 plots the time series of capital misallocation measured log TFP units (solid line) and the log capital utilization rate in the period 1963-2012. We use the first order Taylor expansion in equation (71) to translate the misallocation measure into log TFP units. Both series are HP filtered. 
Figure 3: Business Cycle Variations of the Total Volume of Bank Loan

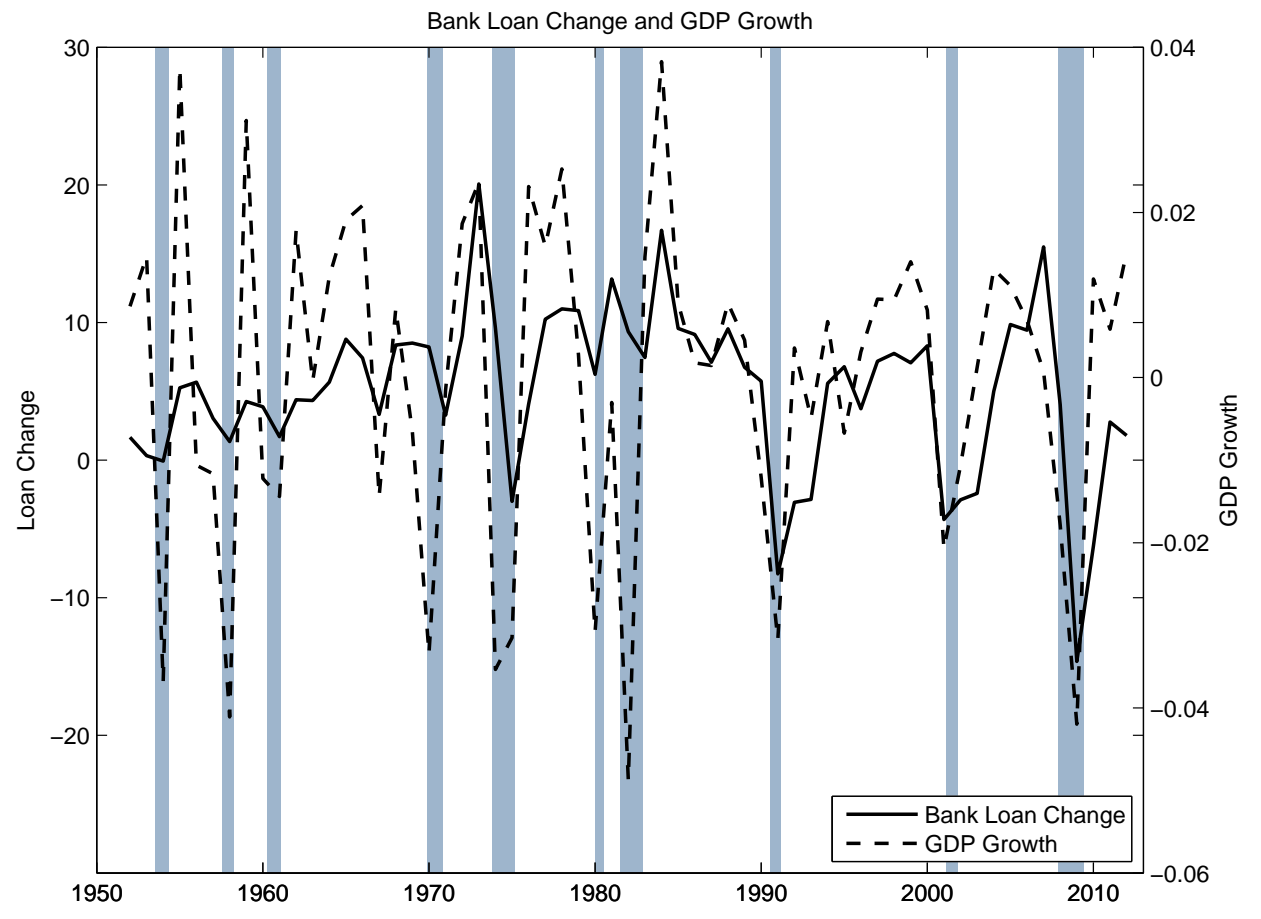

Figure 3 plots the business cycle variations of the total volume of bank loans for all non-financial firms in the US corporate sector. The solid line is the changes in the total volume of bank loans and the dashed line is GDP growth. Shaded areas stand for NBER classified recessions. 
Figure 4: Total Volume of Bank Loan and Capital Misallocation

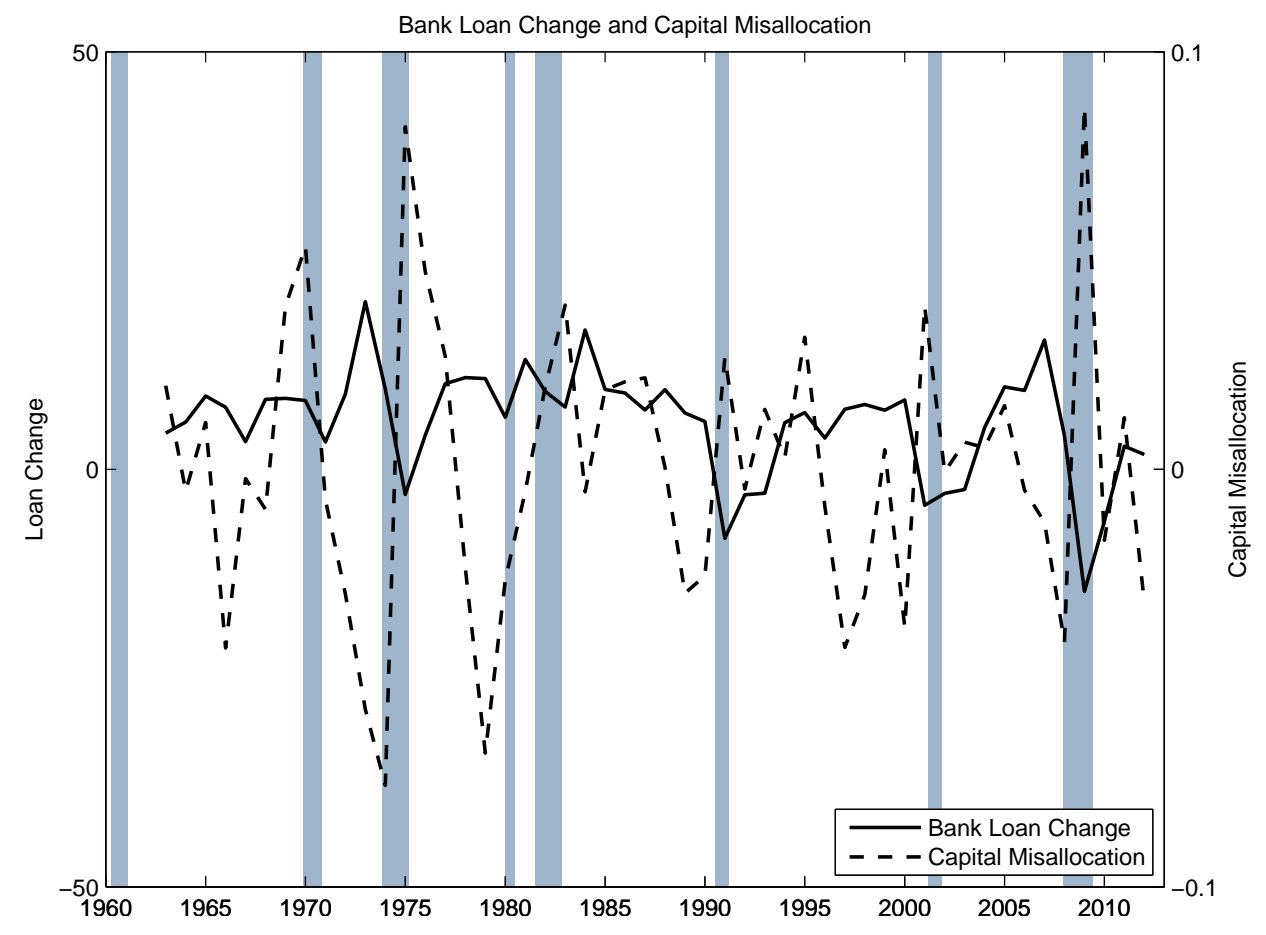

Figure 4 plots the net increases in the total volume of bank loan and our measure of capital misallocation constructed from COMPUSTAT firms during the period 1958-2012. 
Figure 5: Total Volume of Bank Loan and Aggregate Volatility

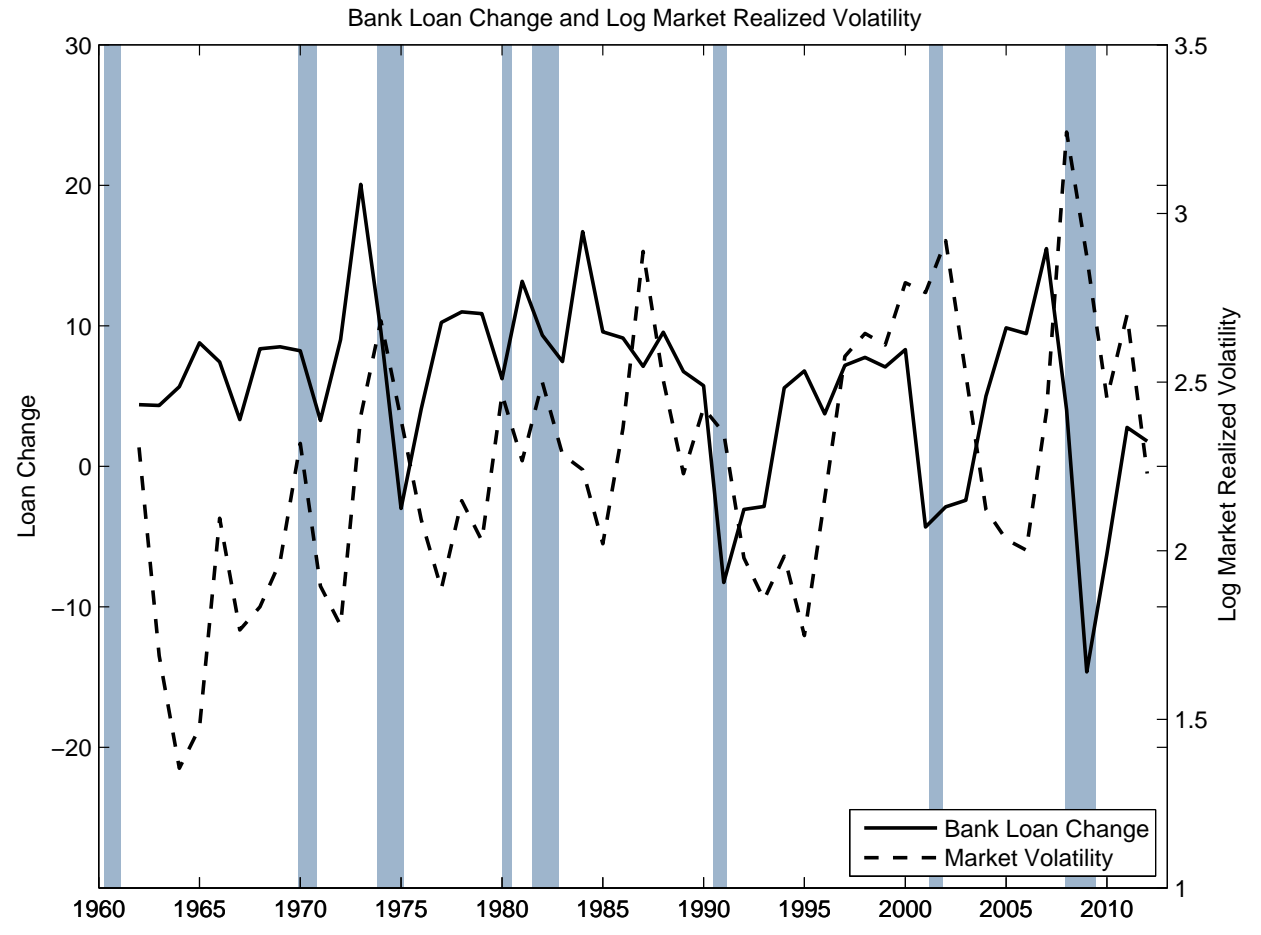

Figure 5 plots the net increases in the total volume of bank loan and stock market volatility in the U.S. during the period 1958-2012. 
Figure 6: Total Volume of Bank Loan and Idiosyncratic Volatility

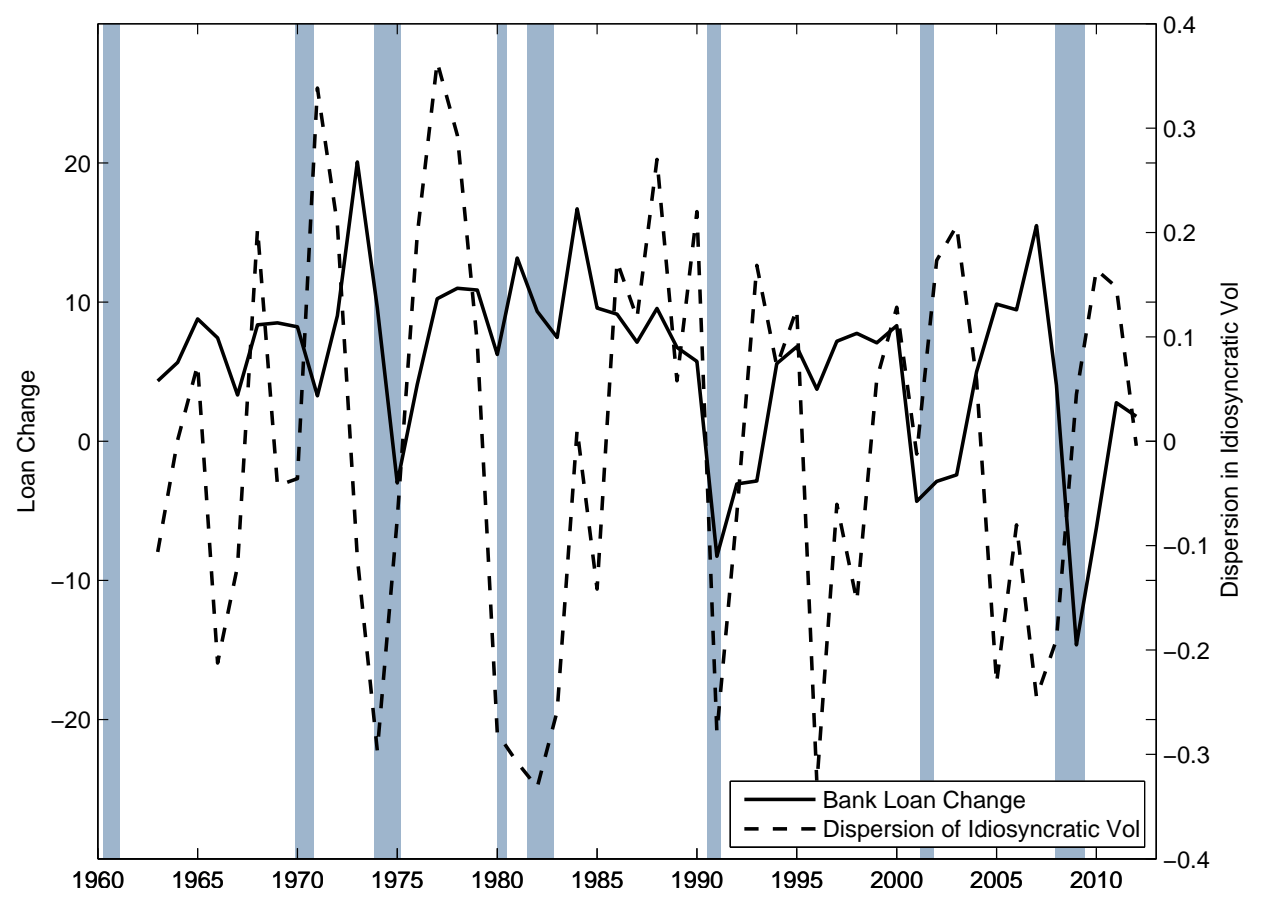

Figure 6 plots the net increases in the total volume of bank loan and the cross-sectional dispersion of firm profit for COMPUSTAT firms. 
Figure 7: Timing of Events

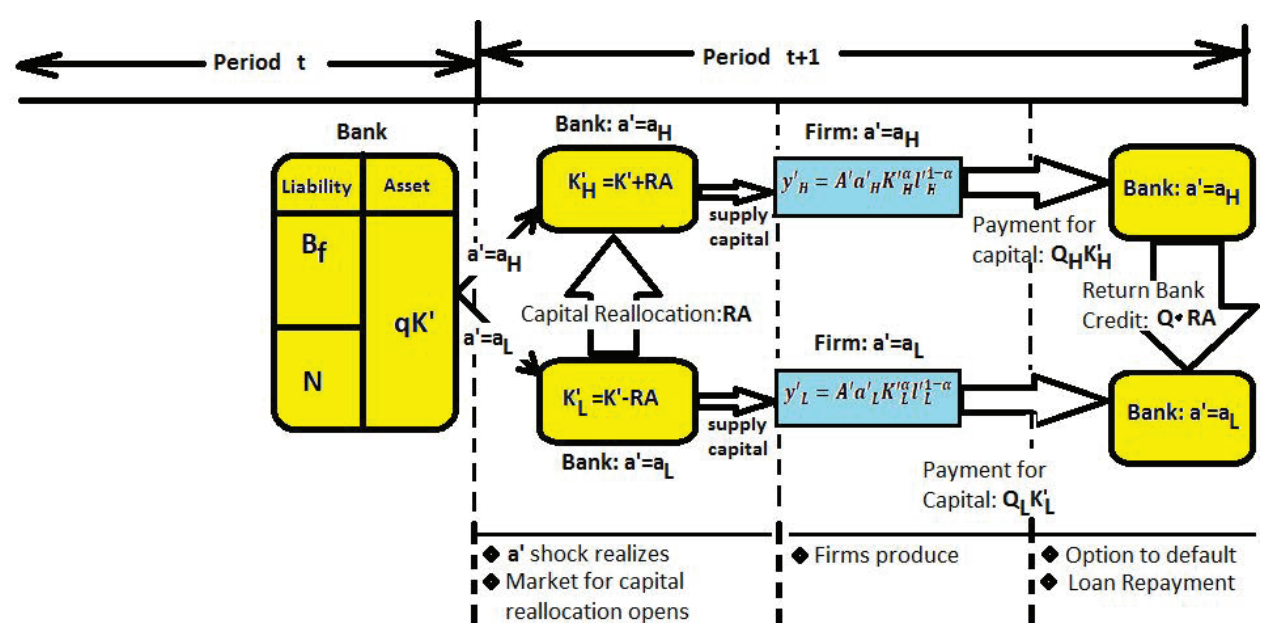

Figure 7 illustrates the timing of event from period $t$ to period $t+1$ in the infinite horizon model. 
Figure 8: Misallocation and Bank Net Worth
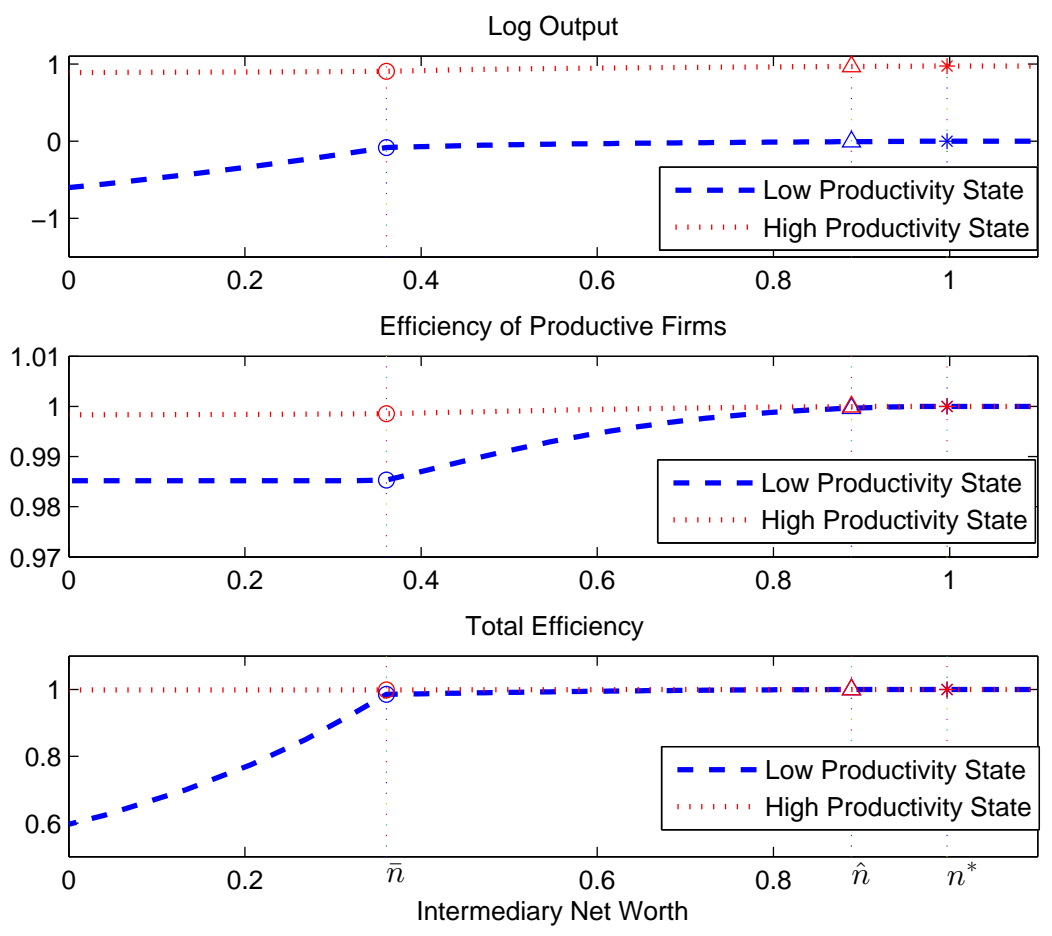

Figure 8 plots the log output (top panel) and the efficiency of capital reallocation (middle and bottom panel) as a function of bank net worth. The top panel is the level of log output as a function of bank net worth for recessions (dashed line) and that for booms (dotted line). The middle panel plots the $f(\phi)$ function and the bottom panel plots $\rho f(\phi)$ as a function of bank net worth. 


\section{Figure 9: Investment and Leverage}
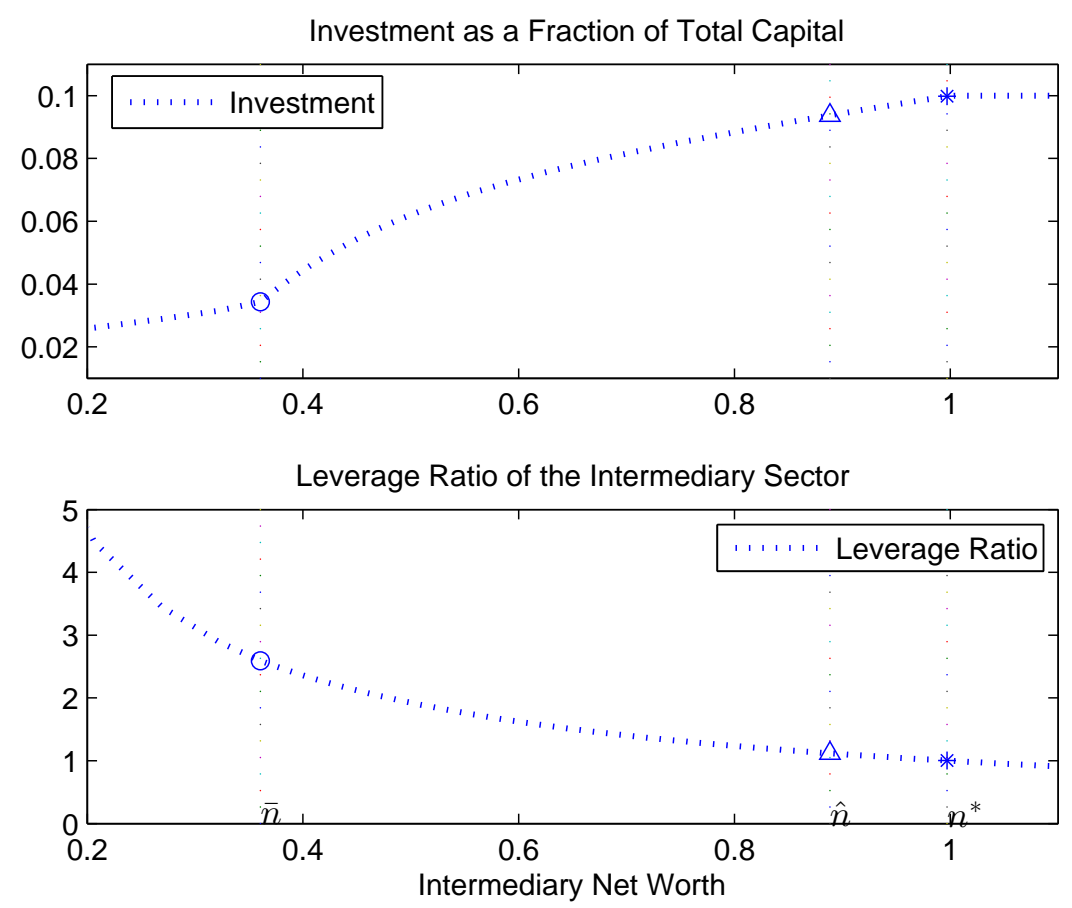

Figure 9 plots the total investment (normalized by capital stock) as a function of bank net worth in the top panel, and the leverage of the banking sector as a function of bank net worth as a function of the bank net worth. 


\section{Figure 10: Mean and Volatility of Output}
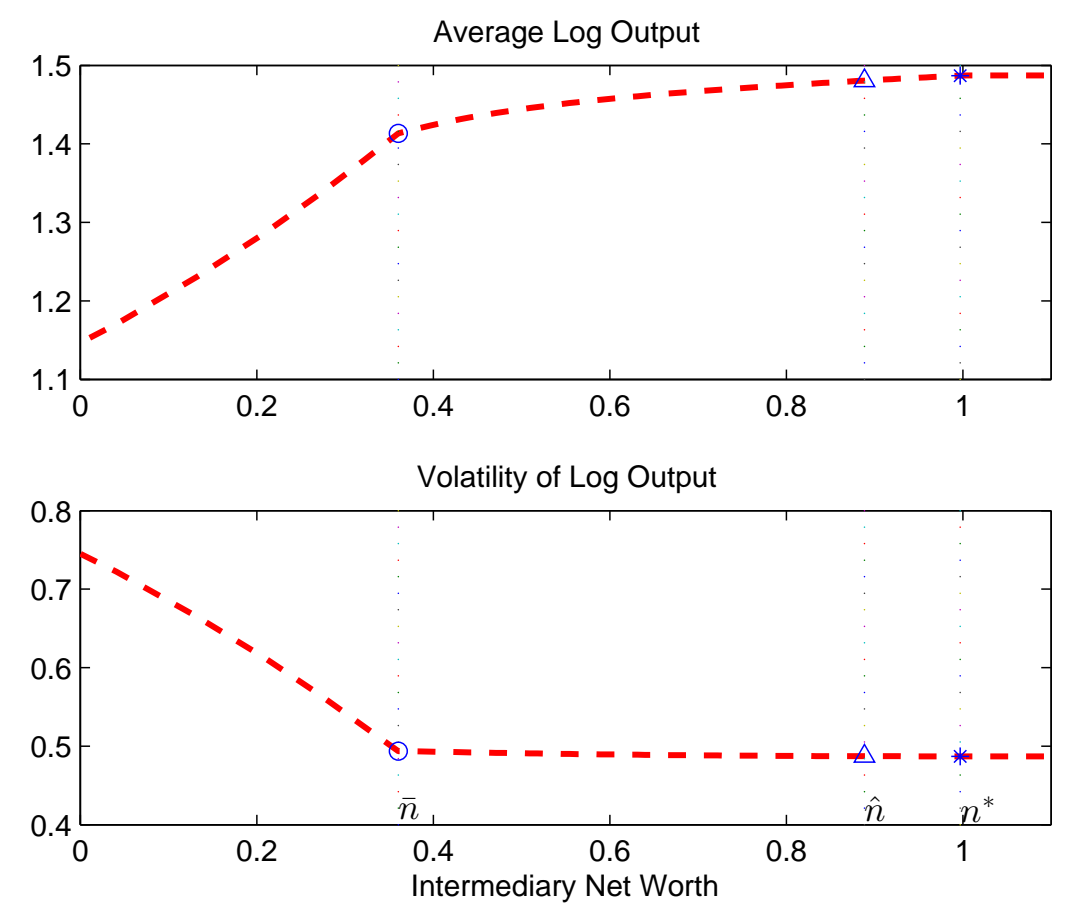

Figure 10 plots the average output (top panel) and the volatility of output (bottom panel) as a function of bank net worth. 


\section{Figure 11: Capital Reallocation and Bank Net Worth}
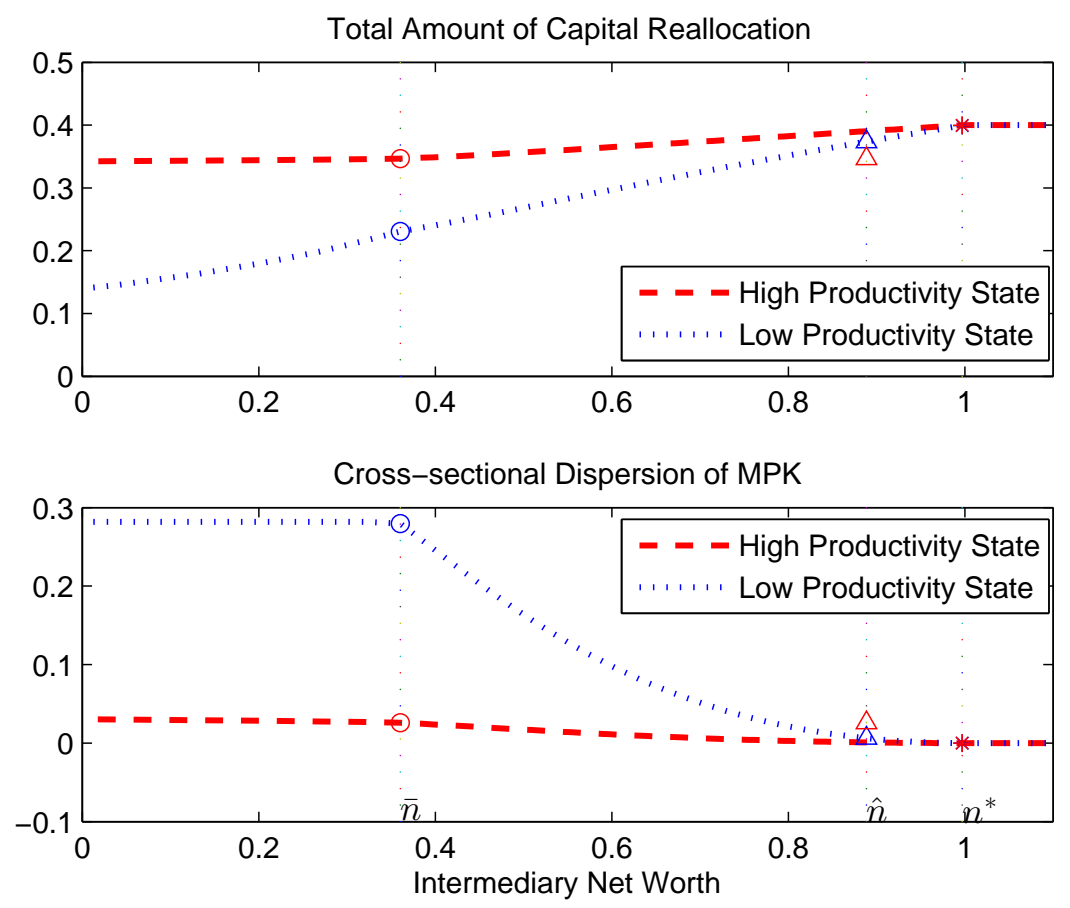

Figure 11 plots the amount of capital reallocation (top panel) and the benefit of capital reallocation measured by the cross-sectional dispersion of the marginal product of capital (bottom panel) as functions of bank net worth. The top panel is the total amount of capital reallocation in booms (dashed line) and recessions (dotted line) as a function of bank net worth. The bottom panel is the cross-sectional dispersion in the marginal product of capital in booms (dashed line) and recessions (dotted line) as a function of bank net worth. 
Table 1: Calibration Parameters

\begin{tabular}{cll}
\hline \hline \multicolumn{2}{l}{ Preference Parameters } \\
\hline$\beta$ & discount rate & 0.97 \\
$\gamma$ & risk aversion & 10 \\
$\psi$ & IES & 2 \\
& & \\
Technology Parameters & $1 / 3$ \\
\hline$\alpha$ & capital share & 1.25 \\
$\eta /(\eta-1)$ & markup & 2.08 \\
$a_{H} / a_{L}$ & ratio of productivity & $10 \%$ \\
$\delta$ & capital depreciation & 0.65 \\
$h$ & adjustment cost & 0.1 \\
$\pi$ & probability of high productivity & 0.71 \\
$A$ & aggregate productivity & \\
& & \\
Parameters of & Financial Frictions & $25 \%$ \\
\hline$\lambda$ & probability of bank exit \\
$\chi$ & Equity injection to banks & 0.12 \\
$\bar{\theta}$ & Fraction of asset divertable & 0.35 \\
$\sigma_{\theta}$ & volatility of $\theta$ & $8 \%$ \\
$\rho_{\theta}$ & autocorrelation of $\theta$ & 0.95 \\
$\omega$ & inter-bank friction & 0.35 \\
\hline \hline
\end{tabular}

Table 1 lists the parameter values we use for the calibration of our model. 
Table 2: Business Cycle Statistics

\begin{tabular}{|c|c|c|c|c|}
\hline Moments & Data & Benchmark Model & TFP Shocks & Dep. Shocks \\
\hline \multicolumn{5}{|l|}{ Average GDP Growth } \\
\hline$E[\Delta \ln Y]$ & $1.8 \%$ & $1.8 \%$ & $1.8 \%$ & $1.8 \%$ \\
\hline \multicolumn{5}{|l|}{ Volatility of GDP Growth } \\
\hline$\sigma[\Delta \ln Y]$ & $3.49 \%$ & $2.53 \%$ & $2.65 \%$ & $2.43 \%$ \\
\hline \multicolumn{5}{|c|}{ Volatility of Consumption Growth } \\
\hline$\sigma[\Delta \ln C]$ & $2.53 \%$ & $2.05 \%$ & $2.24 \%$ & $2.17 \%$ \\
\hline \multicolumn{5}{|c|}{ Volatility of Investment relative to volatility of consumption } \\
\hline$\sigma[\Delta \ln I] / \sigma[\ln C]$ & 5.34 & 2.13 & 2.14 & 2.13 \\
\hline \multicolumn{5}{|c|}{ Correlation of Consumption and Investment } \\
\hline \multicolumn{5}{|c|}{ Autocorrelation of consumption } \\
\hline$A C[\Delta \ln C]$ & $49 \%$ & $42 \%$ & $4.62 \%$ & $85.68 \%$ \\
\hline \multicolumn{5}{|c|}{ Volatility of efficiency of capital reallocation } \\
\hline $\begin{array}{l}\text { Volatility of dispersion of } \mathrm{MH} \\
\sigma[\operatorname{Var}(\ln M P K)]\end{array}$ & $17.09 \%$ & $2.8 \%$ & $0.2 \%$ & $0.2 \%$ \\
\hline \multicolumn{5}{|c|}{ Average Capital Reallocation/Total Investment } \\
\hline$E[\pi R A / I]$ & - & $90 \%$ & $95 \%$ & $93 \%$ \\
\hline $\begin{array}{l}\text { Volatility of Capital Realloca } \\
\sigma[\pi R A / I] \\
\text { Correlation of GDP and Disp }\end{array}$ & $\begin{array}{l}\text { a/Investme } \\
\text { ion of MP }\end{array}$ & $85 \%$ & $11 \%$ & $14 \%$ \\
\hline $\begin{array}{l}\operatorname{Corr}[\Delta \ln Y, \operatorname{Var}(\ln M P K)] \\
\text { Volatility of Tobin } \mathrm{Q}\end{array}$ & $-14.08 \%$ & $-62.34 \%$ & $-9.93 \%$ & $-40.20 \%$ \\
\hline$\sigma[\ln q]$ & - & $3.50 \%$ & 0.53 & 0.43 \\
\hline
\end{tabular}

Table 2 documents the moments of macroeconomic quantities in U.S. data (1930-2009) and those generated by our benchmark model (column "Benchmark Model"), the model with productivity shocks only (TFP shocks), and the model with capital depreciation shocks (Dep Shocks). 
Table 3: Asset Pricing Moments

\begin{tabular}{|c|c|c|}
\hline Moments & Data & Model \\
\hline \multicolumn{3}{|l|}{ Equity Premium } \\
\hline$E\left[\ln R_{M}-R_{f}\right]$ & $5.71 \% *$ & $3.63 \%$ \\
\hline \multicolumn{3}{|c|}{ Volatility of Return on Capital } \\
\hline$\sigma\left[\ln R_{M}\right]$ & $19.79 \%^{*}$ & $3.59 \%$ \\
\hline \multicolumn{3}{|c|}{ Risk-free Interest Rate } \\
\hline$E\left[\ln R_{f}\right]$ & $0.86 \%$ & $1.10 \%$ \\
\hline \multicolumn{3}{|c|}{ Volatility of Risk-free Rate } \\
\hline $\begin{array}{l}\sigma\left[\ln R_{f}\right] \\
\text { Interest Rate Spr }\end{array}$ & $0.97 \%$ & $1.20 \%$ \\
\hline$E\left[\ln R_{I}-R_{f}\right]$ & $0.64 \%$ & $0.88 \%$ \\
\hline \multicolumn{3}{|c|}{ Volatility of Interbank Rate } \\
\hline $\begin{array}{l}\sigma\left[\ln R_{I}\right] \\
\text { Volatility of SDF }\end{array}$ & $2.16 \%$ & $2.08 \%$ \\
\hline$\sigma[M]$ & - & $93.53 \%$ \\
\hline
\end{tabular}

Table 3 documents the asset pricing moments in the data and those generated by our benchmark model. Note that the equity premium and volatility of return in the data are not directly comparable to the moments generated from our model, because our model does not account for financial leverage. 


\section{References}

Ai, H. 2010. Information quality and long-run risk: Asset pricing implications. Journal of Finance LXV(4):1333-1367.

Ai, H., M. M. Croce, and K. Li. 2013. Toward a quantitative general equilibrium asset pricing model with intangible capital. Review of Financial Studies 26(2):491 - 530.

Bansal, R., and A. Yaron. 2004. Risks for the long run: A potential resolution of asset pricing puzzles. Journal of Finance 59(4):1481 - 1509.

Bansal, R., D. Kiku, and A. Yaron. 2010. Long run risks, the macroeconomy, and asset prices. American Economic Review 100(2):542 - 546.

Bansal, R., D. Kiku, I. Shaliastovich, and A. Yaron. Volatility, the macroeconomy, and asset prices. Working paper University of Pennsylvania 2012.

Bernanke, B., and M. Gertler. 1989. Agency costs, net worth, and business fluctuations. American Economic Review 79(1):14-31.

Bernanke, B. S., M. Gertler, and S. Gilchrist. The financial accelerator in a quantitative business cycle framework. In Handbook of Macroeconomics volume 1, Part C pages 1341 - 1393. Elsevier 1999.

Bloom, N. 2009. The impact of uncertainty shocks. Econometrica 77(3):623-685.

Brunnermeier, M. K., and Y. Sannikov. 2014. A macroeconomic model with a financial sector. American Economic Review 104(2):379-421.

Brunnermeier, M. K., T. Eisenbach, and Y. Sannikov. Macroeconomics with financial frictions: A survey. Working paper 2012.

Campbell, J. Y., M. Lettau, B. G. Malkiel, and Y. Xu. 2001. Have individual stocks become more volatile? an empirical exploration of idiosyncratic risk. Journal of Finance 56(1):1 $-43$.

Carlstrom, C. T., and T. S. Fuerst. 1997. Agency costs, net worth, and business fluctuations: A computable general equilibrium analysis. The American Economic Review 87(5):893910 . 
Chen, K., and Z. Song. 2013. Financial frictions on capital allocation: A transmission mechanism of tfp fluctuations. Journal of Monetary Economics 60:683 - 703.

Croce, M. M. Long-run productivity risk: A new hope for production-based asset pricing. Working paper University of North Carolina-Chapel Hill 2010.

Eisfeldt, A., and A. Rampini. 2008. Managerial incentives, capital reallocation, and the business cycle. Journal of Financial Economics 87:177-199.

Eisfeldt, A. L., and A. A. Rampini. 2006. Capital reallocation and liquidity. Journal of Monetary Economics 53:369 - 399.

Favilukis, J., and X. Lin. Infrequent renegotiation of wages: A solution to several asset pricing puzzles. Working paper London School of Economics and Ohio State University 2013.

Frankel, M. 1962. The production function in allocation and growth: A synthesis. The American Economic Review 52(5).

Fuchs, W., B. Green, and D. Papanikolaou. Adverse selection, slow moving capital, and misallocation. Working paper University of California Berkeley and Northwestern University 2013.

Gertler, M., and P. Karadi. 2011. A model of unconventional monetary policy. Journal of Monetary Economics 58(1):17-34.

Gertler, M., and N. Kiyotaki. 2010. Financial intermediation and credit policy in business cycle analysis. Handbook of Monetary Economics 3:547 - 599.

Gourio, F. 2012. Disasters risk and business cycles. American Economic Review 102(6): $2734-2766$.

He, Z., and A. Krishnamurthy. 2012. A model of capital and crises. Review of Economic Studies 79(2):735 - 777 .

He, Z., and A. Krishnamurthy. 2013. Intermediary asset pricing. American Economic Review $103(2): 732-70$.

He, Z., and A. Krishnamurthy. A macroeconomic framework for quantifying systemic risk. Working paper University of Chicago and Northwestern University 2014. 
Hopenhayn, H., and Neumeyer. 2008. Productivity and distortions.

Hsieh, C.-T., and P. J. Klenow. 2009. Misallocation and manufacturing tfp in china and india. The Quaterly Journal of Economics CXXIV(4):1403 - 1448.

Jermann, U., and V. Quadrini. 2012. Macroeconomic effects of financial shocks. American Economic Review 102(1):238-71.

Kaltenbrunner, G., and L. A. Lochstoer. 2010. Long-run risk through consumption smoothing. Review of Financial Studies 23:3141 - 3189.

Kiyotaki, N., and J. H. Moore. 1997. Credit cycles. Journal of Political Economy 105(3): $211-248$.

Kiyotaki, N., and J. H. Moore. 2005. Liquidity and asset prices. International Economic Review 46:317-349.

Kiyotaki, N., and J. H. Moore. Liquidity, business cycle, and monetary policy. Manuscript Princeton University and Edinburgh University 2008.

Kocherlakota, N. R. 2000. Creating business cycles through credit constraints. Federal Reserve Bank of Minneapolis Quarterly Review 24(3).

Kogan, L., and D. Papanikolaou. 2012a. Economic activity of firms and asset prices. The Annual Review of Financial Economics 4:1 - 24.

Kogan, L., and D. Papanikolaou. 2012b. Growth opportunities, technology shocks and asset prices. Journal of Finance, Forthcoming.

Krishnamurthy, A. 2003. Collateral constraints and the amplification mechanism. Journal of Economic Theory 111(2):277 - 292.

Kung, H., and L. Schmid. 2013. Innovation, growth, and asset prices. Journal of Finance Forthcoming.

Kurlat, P. 2013. Lemons markets and the transmission of aggregate shocks. American Economic Review 103(4):1463-89.

Li, K. Asset pricing with a financial sector. Working paper Duke University 2013. 
Li, S., and T. Whited. 2014. Capital reallocation and adverse selection. Working Paper, University of Rochester.

Ljungqvist, L., and T. Sargent. Recursive Macroeconomic Theory. MIT Press 2004.

Mendoza, E. G. 2010. Sudden stops, financial crises, and leverage. American Economic Review 100(5):1941-66.

Papanikolaou, D. 2001. Investment shocks and asset prices. Journal of Political Economy 119(4):639-685.

Quadrini, V. 2011. Financial frictions in macroeconomic fluctuations. Economic Quaterly $97(3): 209-254$.

Rampini, A., and S. Viswanathan. 2014. Financial intermediary capital. Working Paper, Duke University.

Romer, P. M. 1986. Increasing returns and long-run growth. Journal of Political Economy 94(5):1002 - 1037.

Shourideh, A., and A. Zetlin-Jones. External financing and the role of financial frictions over the business cycle: Measurement and theory. Working paper University of Pennsylvania and Carnegie Mellon University 2012.

Stokey, N. L., and R. E. Lucas. Recursive methods in economic dynamics. Harvard University Press 1989.

Tallarini, T. D. June 2000. Risk-sensitive eral business cycles. Journal of Monetary Economics $45(3)$. 